Article

\title{
Design, Synthesis, and Neuroprotective Effects of a Series of Pyrazolines against 6-Hydroxydopamine-Induced Oxidative Stress
}

\author{
Ahmet Özdemir ${ }^{1, *(\mathbb{C})}$, Belgin Sever $^{1}{ }^{(\mathbb{D})}$, Mehlika Dilek Altıntop ${ }^{1}{ }^{(\mathbb{D}}$, Elif Kaya Tilki ${ }^{2}$ and \\ Miriş Dikmen ${ }^{2}$ \\ 1 Department of Pharmaceutical Chemistry, Faculty of Pharmacy, Anadolu University, Eskişehir 26470, \\ Turkey; belginsever@anadolu.edu.tr (B.S.); mdaltintop@anadolu.edu.tr (M.D.A.) \\ 2 Department of Pharmacology, Faculty of Pharmacy, Anadolu University, Eskişehir 26470, Turkey; \\ elif_kaya@anadolu.edu.tr (E.K.T.); mirisd@anadolu.edu.tr (M.D.) \\ * Correspondence: ahmeto@anadolu.edu.tr; Tel.: +90-222-335-0580 (ext. 3780)
}

Received: 26 July 2018; Accepted: 22 August 2018; Published: 27 August 2018

check for updates

\begin{abstract}
Parkinson's disease (PD) is a chronic, progressive, and age-related neurodegenerative disorder characterized by the loss of midbrain dopaminergic neurons caused by the accumulation of free radicals and oxidative stress. Based on the neuroprotective properties of 2-pyrazoline derivatives, in the current work, 1-(phenyl/4-substituted phenyl)-3-(2-furanyl/thienyl)-5-aryl-2-pyrazolines (3a-i, 4a-i) were synthesized via the cyclization of the chalcones $(\mathbf{1}, \mathbf{2})$ with suitable phenylhydrazine hydrochloride derivatives. All these compounds were investigated for their neuroprotective effects using an in vitro 6-hydroxydopamine (6-OHDA)-induced neurotoxicity model of PD in the rat pheochromocytoma (PC-12) Adh cell line. In addition, some different pharmacokinetic parameters of all compounds were in silico predicted by the QikProp module of Schrödinger's Maestro molecular modeling package. 4-Methylsulfonylphenyl substituted compounds $3 \mathrm{~h} \mathrm{(20 \% )}$ and $4 \mathrm{~h}(23 \%)$ were determined as the most promising neuroprotective agents related to their inductive roles in cell viability when compared with the 6-OHDA-positive control group (43\% and 42\%, respectively). Moreover, in silico pharmacokinetic results indicated that all compounds were within the acceptable range intended for human use. According to both in vitro and in silico studies, compounds $3 \mathrm{~h}$ and $4 \mathrm{~h}$ draw attention as potential orally bioavailable therapeutic drug candidates against neurodegeneration in PD.
\end{abstract}

Keywords: Parkinson's disease; neurodegeneration; 2-pyrazoline; chalcone; 6-hydroxydopamine; pharmacokinetic parameters

\section{Introduction}

Neurodegenerative diseases (NDDs) are rapidly rising in prevalence in many countries and are highly linked to the expected aging of the population, because these disorders mainly occur in the elderly. NDDs can be classified according to extrapyramidal and pyramidal movement problems or cognitive and behavioral problems. The most common forms of NDDs are Alzheimer's disease (AD), Parkinson's disease (PD), amyotrophic lateral sclerosis (ALS), Huntington's disease (HD), and dementia with Lewy bodies (DLB) [1-4]. These diseases reveal common pathological properties such as the formation of insoluble protein-based aggregates in deteriorated neurons and glial cells, whereas there is a big difference in clinical features of patients suffering from them [5].

PD, firstly described as "paralysis agitans" by James Parkinson in 1817, is the second most common NDD affecting $2-3 \%$ of those $>65$ years of age [6,7]. The cause of PD is not clear, but the defects in mitochondrial functions and brain iron regulation, inflammation, and energy metabolism 
problems have been proven to be substantial in underlying mechanisms [8]. It is neuropathologically characterized by the loss of progressive dopaminergic neurons in the substantia nigra pars compacta and the accumulation of aggregated $\alpha$-synuclein protein forming intracellular Lewy bodies in affected regions [8,9]. Moreover, the loss of dopaminergic neurons is associated with the decrease in the activity of catalase enzymes and the increase of monoamine oxidase-B (MAO-B) in glial cells. These enzymatic changes lead to emerging oxidative stress through the formation of higher levels of quinones, peroxides, and other reactive oxygen species (ROS), which then contribute to lipid and protein peroxidation and finally to neuronal death [8-11].

The cardinal clinical features of PD patients are motor impairment, including resting tremors, muscular rigidity, bradykinesia, and postural instability. Furthermore, these patients also mainly have speech and swallowing difficulties, a masklike facial expression, and micrographia [12,13]. Approved treatment procedures for PD to date, such as pharmacotherapy and neurosurgery, have mainly focused on the recovery of these clinical symptoms. However, recently a major approach for the treatment is to discover new beneficial, potential, and disease-modifying drugs targeting the underlying mechanisms related to the neurodegenerative process of PD [14-16].

The main aspect of oxidative stress in PD has been investigated with toxin-based models such as 1-methyl-4-phenyl-1,2,3,6-tetrahydropyridine (MPTP) and 6-hydroxydopamine (6-OHDA). 6-OHDA (Figure 1) is a neurotoxin, which is capable of generating ROS in neurons, and is detected in the urine of PD patients treated with long-term L-3,4-dihydroxyphenylalanine (L-DOPA) (Figure 1), which is the natural precursor of dopamine (Figure 1) and the typically prescribed drug for the symptomatic treatment of PD. Neurodegeneration with a 6-OHDA-based model can mimic idiopathic PD pathogenesis in vitro, as well as in vivo. The primary advantages of this model are measurable motor deficit (rotation) and proven usage in the pharmacological screening of compounds effective on dopamine and its receptors [17-20].<smiles>NCCc1cc(O)c(O)cc1O</smiles>

6-OHDA

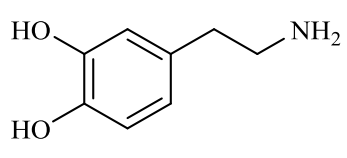

Dopamine<smiles>N[C@@H](Cc1ccc(O)c(O)c1)C(=O)O</smiles>

L-DOPA

Figure 1. Chemical structures of 6-hydroxydopamine (6-OHDA), dopamine, and L-3,4-dihydroxyphenylalanine (L-DOPA).

Rat pheochromocytoma (PC-12) cells have been widely used for in vitro studies exploring the mechanisms of NDDs. PC-12 Adh is a rat pheochromocytoma-derived cell-line, which responds to nerve growth factor (NGF) by switching from an immature chromaffin-cell-like phenotype to a sympathetic-neuron-like one. Therefore, this cell line has been widely used as an in vitro assay system for screening the neuroprotective effects of compounds [21-24].

Pyrazoline is a five-membered heterocyclic ring bearing two adjacent nitrogen atoms and one endocyclic double bond. It has three tautomeric forms called as 1-pyrazoline, 2-pyrazoline, and 3-pyrazoline, but among them, 2-pyrazoline is the most common one. 2-Pyrazoline-based compounds possess a wide range of pharmacological applications including antiepileptic, antidepressant, and anti-neurodegenerative activities. Moreover, these compounds can cross the blood-brain barrier (BBB) easily by means of their lipophilic characters [25-28].

Having the above aspects in mind, a series of 2-pyrazoline-based compounds $3 \mathbf{a}-\mathbf{i}$ and $4 \mathbf{a}-\mathbf{i}$ were designed and synthesized via the reaction of chalcones $(\mathbf{1}, \mathbf{2})$. All the compounds were in vitro evaluted for their neuroprotective potentials against 6-OHDA-induced neurotoxicity in PC-12 Adh cells. In addition, in silico absorption, distribution, metabolism, and excretion (ADME) studies were performed to predict their physicochemical properties particularly their abilities to cross the BBB. 


\section{Results and Discussion}

The synthesis of new pyrazoline derivatives $(\mathbf{3 a - i}, \mathbf{4 a - i})$ followed the general pathway depicted in Scheme 1. Initially, 1,3-diaryl-substituted chalcones $(\mathbf{1}, \mathbf{2})$ were synthesized via the base-catalyzed Claisen-Schmidt condensation of 2-acetylfuran/2-acetylthiophene with the appropriate aromatic aldehydes [29-32]. Then, the final compounds, 1-(phenyl/4-substituted phenyl)-3-(2-furanyl/thienyl)5-aryl-2-pyrazolines (3a-i, $\mathbf{4 a - i})$, were obtained via the cyclization of the chalcones $(\mathbf{1}, \mathbf{2})$ with suitable phenylhydrazine hydrochloride derivatives in the presence of hot acetic acid [33].
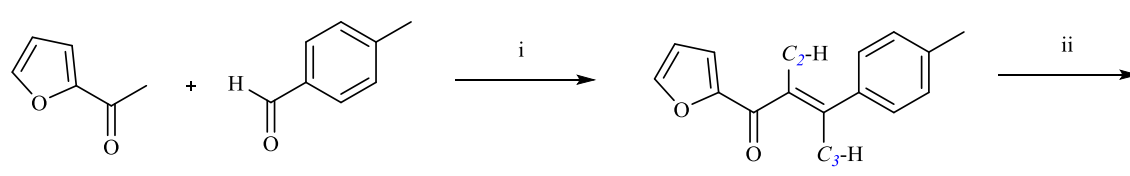

1

\begin{tabular}{cl}
\hline Compound & $\mathbf{R}$ \\
\hline 3a & $\mathrm{H}$ \\
$\mathbf{3 b}$ & $\mathrm{CN}$ \\
$\mathbf{3 c}$ & $\mathrm{F}$ \\
$\mathbf{3 d}$ & $\mathrm{Cl}$ \\
$\mathbf{3 e}$ & $\mathrm{Br}$ \\
$\mathbf{3 f}$ & $\mathrm{CH}$ \\
$\mathbf{3 g}$ & $\mathrm{O}_{3} \mathrm{CH}_{3}$ \\
$\mathbf{3 h}$ & $\mathrm{SO}_{2} \mathrm{CH}_{3}$ \\
$\mathbf{3 i}$ & $\mathrm{SO}_{2} \mathrm{NH}_{2}$ \\
&
\end{tabular}
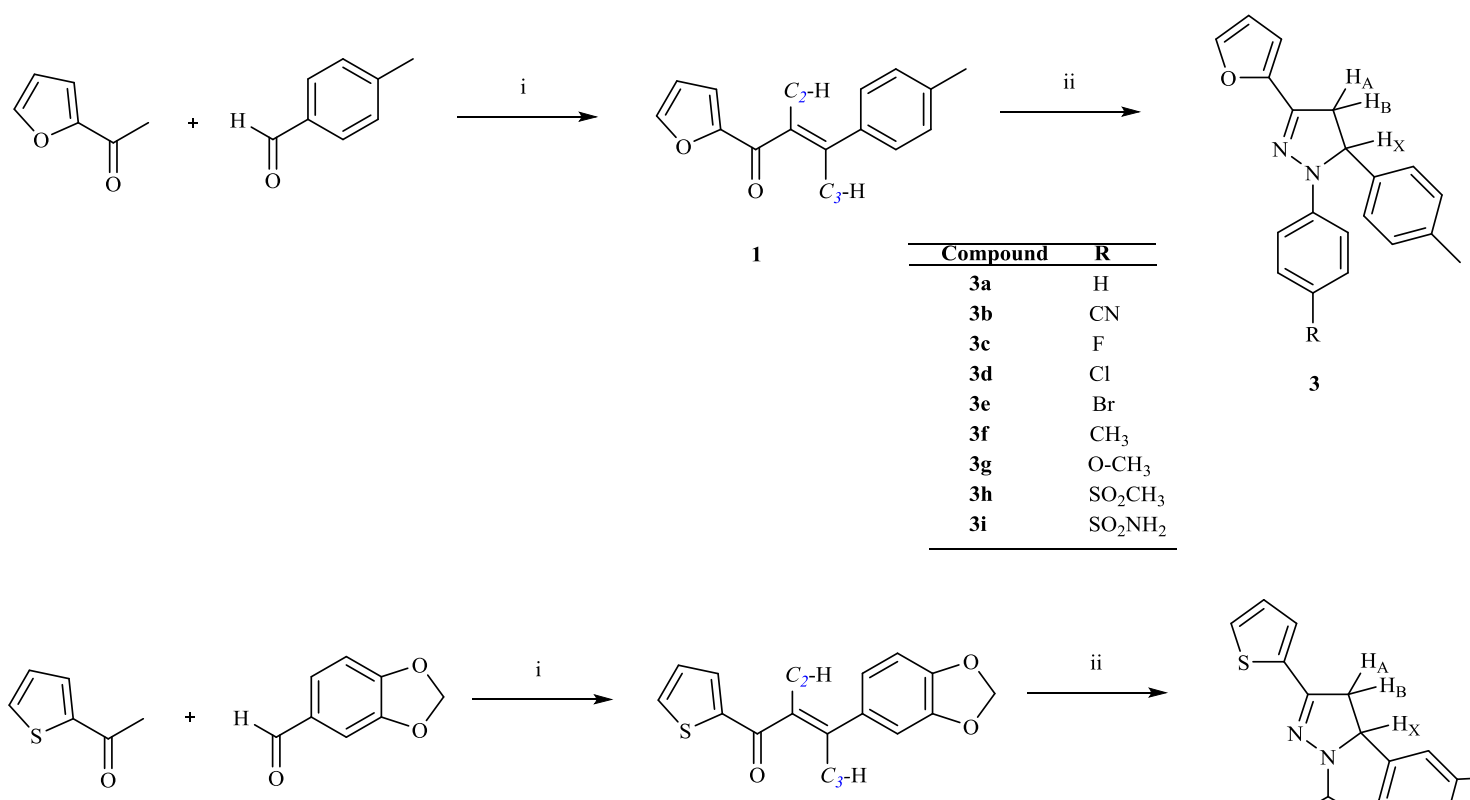<smiles>Cc1cccs1</smiles>

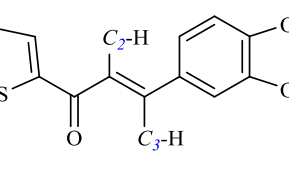

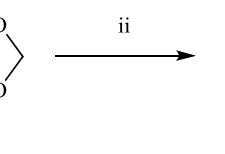

\begin{tabular}{cl}
\hline Compound & $\mathbf{R}$ \\
\hline $\mathbf{4 a}$ & $\mathrm{H}$ \\
$\mathbf{4 b}$ & $\mathrm{CN}$ \\
$\mathbf{4} \mathbf{c}$ & $\mathrm{F}$ \\
$\mathbf{4 d}$ & $\mathrm{Cl}$ \\
$\mathbf{4}$ & $\mathrm{Br}$ \\
$\mathbf{4 f}$ & $\mathrm{CH}$ \\
$\mathbf{4} \mathbf{g}$ & $\mathrm{O}_{3} \mathrm{CH}_{3}$ \\
$\mathbf{4 h}$ & $\mathrm{SO}_{2} \mathrm{CH}_{3}$ \\
$\mathbf{4} \mathbf{i}$ & $\mathrm{SO}_{2} \mathrm{NH}_{2}$ \\
\hline
\end{tabular}

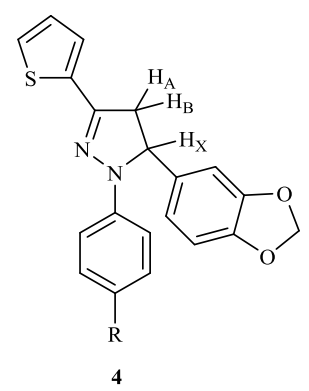

Scheme 1. The synthetic route for the preparation of the compounds $(\mathbf{1}, \mathbf{2}, \mathbf{3 a} \mathbf{a}-\mathbf{i}, \mathbf{4 a}-\mathbf{i})$. Reagents and conditions: (i) $40 \%(w / v)$ sodium hydroxide, ethanol, rt, $24 \mathrm{~h}$; (ii) appropriate phenylhydrazine hydrochloride derivative, $\mathrm{CH}_{3} \mathrm{COOH}$, reflux, $8 \mathrm{~h}$.

The structures of all the compounds were elucidated by FTIR, ${ }^{1} \mathrm{H}$ NMR, ${ }^{13} \mathrm{C}$ NMR, mass spectral data, and elemental analyses. In the ${ }^{1} \mathrm{H}$ NMR spectra of the compounds, $3 \mathbf{a}-\mathbf{i}$ and $4 \mathbf{a}-\mathbf{i}$, the $\mathrm{CH}_{2}$ protons of the 2-pyrazoline ring resonated as a pair of doublets of doublets at 2.95-3.20 ppm $\left(\mathrm{H}_{\mathrm{A}}\right)\left(J_{A M}=17.13-17.64 \mathrm{~Hz}, J_{A X}=4.65-7.41 \mathrm{~Hz}\right)$ and $3.69-3.96 \mathrm{ppm}\left(\mathrm{H}_{\mathrm{M}}\right)\left(J_{M A}=17.18-17.64 \mathrm{~Hz}\right.$, $\left.J_{M X}=11.85-12.09 \mathrm{~Hz}\right)$. The $\mathrm{CH}$ proton appeared as a doublet of doublets at 5.29-5.59 $\mathrm{ppm}\left(\mathrm{H}_{\mathrm{X}}\right)$ $\left(J_{M X}=11.76-12.09 \mathrm{~Hz}, J_{A X}=4.68-7.38 \mathrm{~Hz}\right)$ owing to the vicinal coupling with two magnetically non-equivalent protons of the methylene group at the 4 th position of the pyrazoline ring. All the other aromatic and aliphatic protons were observed in the expected regions. Mass spectral data and elemental analysis were also in agreement with the proposed structures of the compounds [33,34].

According to the $\mathrm{IC}_{50}$ values given in Table 1, apart from compound 1, treatment with the compounds at $100 \mu \mathrm{g} / \mathrm{mL}$ did not reduce cell viability significantly. The compounds demonstrated their protective effects against cell death in differentiated PC-12 Adh cells treated with 6-OHDA 
$(150 \mu \mathrm{M})$ for $24 \mathrm{~h}$. The reduction in cell viability was determined as 43\% with 6-OHDA (150 $\mu \mathrm{M})$ and $36,29,35,37,30,31,29,20,30 \%$ with compounds 3a-i (100 $\mu \mathrm{g} / \mathrm{mL})$, respectively (Figure 2; Table 2). However, compound 1 was found to be highly cytotoxic, and it reduced cell viability with the values of $97 \%(100 \mu \mathrm{g} / \mathrm{mL})$ and $40 \%(10 \mu \mathrm{g} / \mathrm{mL})$. In addition, the reduction in cell viability was evaluated as $34.1 \%$ with compound 2 and $59,54,76,56,41,62,69,23,87 \%$ with compounds $4 \mathbf{a}-\mathbf{i}(100 \mu \mathrm{g} / \mathrm{mL})$, respectively, when compared with 6-OHDA $(150 \mu \mathrm{M})(42.13 \%)$ (Figure 2; Table 2). According to these results, all the compounds reduced cell viability compared with the control group after $24 \mathrm{~h}$ 6-OHDA exposure $\left({ }^{*} p<0.05,{ }^{* * *} p<0.001,{ }^{* * *} p<0.0001\right.$ for compounds 1 and $3 \mathbf{a}-\mathbf{i}$; ${ }^{* * *} p<0.0001$ for compounds 2 and $4 \mathbf{a}-\mathbf{i}$ ). Compounds $3 \mathbf{a}-\mathbf{i}, \mathbf{2}$, and $4 \mathrm{~h}$ might have neuroprotective potential against 6-OHDA induced neurotoxicity in PC-12 Adh cells but only the induction in cell viability percentage with compounds $3 \mathrm{~h}$ and $4 \mathrm{~h}$ was found significant compared with the 6-OHDA-positive control group related to the statistical analysis $\left({ }^{* *} p<0.01\right)$. This outcome pointed out that the presence of 4-methylsulfonylphenyl moiety enhanced the neuroprotective potency of the 2-pyrazoline ring as observed in both compounds $3 \mathrm{~h}$ and $4 \mathrm{~h}$.

Table 1. $\mathrm{IC}_{50}$ values of compounds $1,2,3 \mathbf{a}-\mathbf{i}$ and $4 \mathbf{a}-\mathbf{i}$ and 6-OHDA according to the cell viability assay.

\begin{tabular}{cccc}
\hline Compound & $\mathrm{IC}_{\mathbf{5 0}}(\boldsymbol{\mu g} / \mathbf{m L})$ & Compound & IC $_{\mathbf{5 0}}(\boldsymbol{\mu g} / \mathbf{m L})$ \\
\hline $\mathbf{1}$ & 12 & $\mathbf{2}$ & 345 \\
$\mathbf{3 a}$ & $>400$ & $\mathbf{4 a}$ & $>400$ \\
$\mathbf{3 b}$ & 204 & $\mathbf{4 b}$ & $>400$ \\
$\mathbf{3 c}$ & 353 & $\mathbf{4 c}$ & $>400$ \\
$\mathbf{3 d}$ & $>400$ & $\mathbf{4 d}$ & $>400$ \\
$\mathbf{3 e}$ & 398 & $\mathbf{4 e}$ & $>400$ \\
$\mathbf{3 f}$ & $>400$ & $\mathbf{4 f}$ & 239 \\
$\mathbf{3 g}$ & $>400$ & $\mathbf{4 g}$ & 252 \\
$\mathbf{3 h}$ & $>400$ & $\mathbf{4 h}$ & $>400$ \\
$3 \mathbf{i}$ & 205 & $\mathbf{4 i}$ & $>400$ \\
6-OHDA & $150 \mu \mathrm{M}$ & 6-OHDA & $150 \mu \mathrm{M}$ \\
\hline
\end{tabular}

Table 2. Cell viability values of 6-OHDA and compounds 1, 2, 3a-i, $\mathbf{4 a - i}$ according to the cell viability assay results. The results of the cell viability were presented as a \% of the control (the O.D. value).

\begin{tabular}{cccc}
\hline Compound & Cell Viability $\%$ & Compound & Cell Viability $\%$ \\
\hline Control & 100 & Control & 100 \\
$6-$ OHDA & 57 & $6-$ OHDA & 58 \\
$\mathbf{1}(100 \mu \mathrm{g} / \mathrm{mL})$ & 3 & $\mathbf{2}$ & 66 \\
$\mathbf{1}(10 \mu \mathrm{g} / \mathrm{mL})$ & 60 & $\mathbf{4 a}$ & 41 \\
$\mathbf{3 a}$ & 64 & $\mathbf{4 b}$ & 46 \\
$\mathbf{3 b}$ & 71 & $\mathbf{4 c}$ & 24 \\
$\mathbf{3 c}$ & 65 & $\mathbf{4 d}$ & 44 \\
$\mathbf{3 d}$ & 63 & $\mathbf{4 e}$ & 59 \\
$\mathbf{3 e}$ & 70 & $\mathbf{4 f}$ & 38 \\
$\mathbf{3 f}$ & 69 & $\mathbf{4 g}$ & 31 \\
$\mathbf{3 g}$ & 71 & $\mathbf{4 h}$ & 77 \\
$\mathbf{3 h}$ & 80 & $\mathbf{4 i}$ & 13 \\
$\mathbf{3 i}$ & 70 & & \\
\hline
\end{tabular}




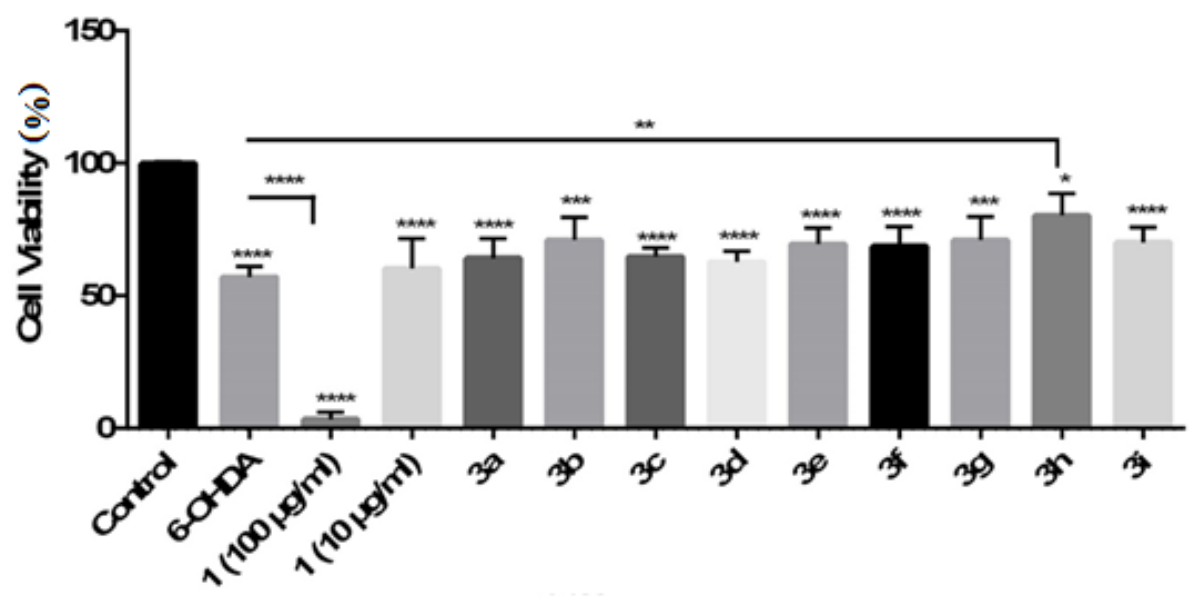

(A)

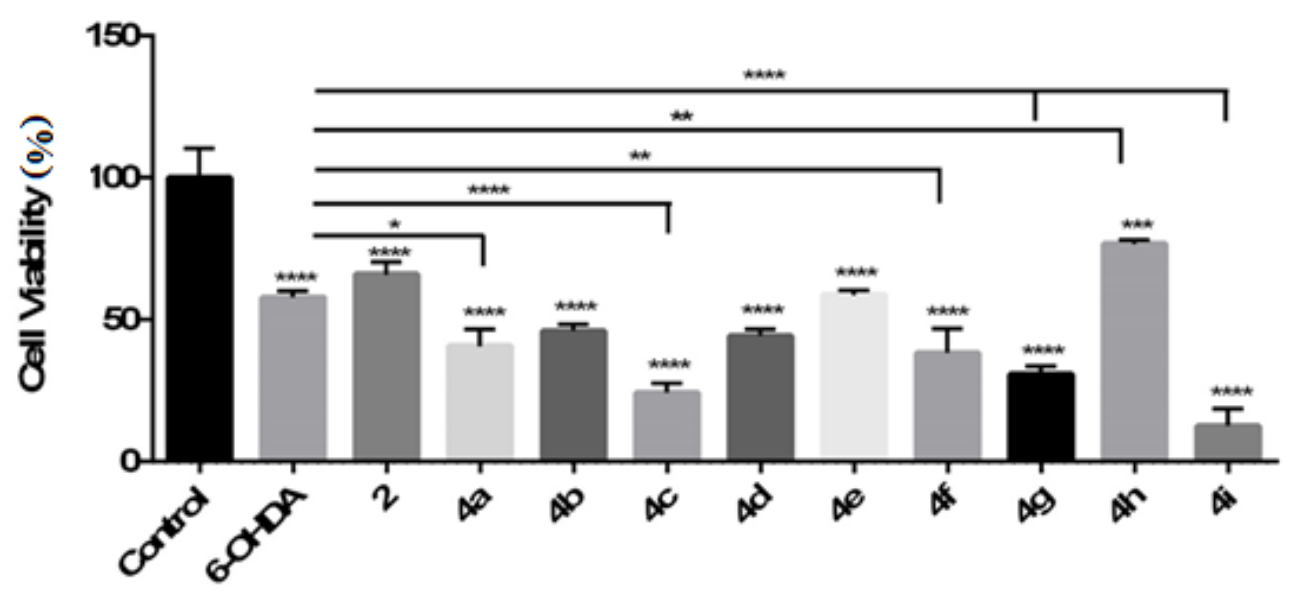

(B)

Figure 2. Neuroprotective effects of compounds 1 and $\mathbf{3 a - i}(\mathbf{A}) ; \mathbf{2}$ and $\mathbf{4 a - i}(\mathbf{B})$ against 6-OHDA induced neurotoxicity. PC-12 Adh cells were treated with $100 \mu \mathrm{g} / \mathrm{mL}$ concentration of the compounds for $6 \mathrm{~h}$ before exposure to $150 \mu \mathrm{M}$ 6-OHDA for $24 \mathrm{~h}$. The cell viability was detected at the 24th hour. The results of the cell viability were presented as a $\%$ of the control (the O.D. value). Data are shown as mean \pm SD of three experiments. $\left((n=8), p>0.05\right.$ n.s., ${ }^{*} p<0.05,{ }^{* *} p<0.01,{ }^{* * *} p<0.001$, and $\left.{ }^{* * * *} p<0.0001\right)$.

ADME properties of compounds $\mathbf{1}, \mathbf{2}, \mathbf{3 a}-\mathbf{i}$, and $\mathbf{4 a - i}$ were in silico assessed to enlighten the biological, pharmaceutical, and drug similarities of these compounds. The results given in Table 3 were found to be within the acceptable range intended for human use, making these derivatives promising drug candidates [35]. All these compounds were detected to exhibit excellent absorption \% (92-100\%) in human oral absorption on a $0-100 \%$ scale, and based on the parameters of the brain/blood partition coefficient (QPlogBB) ( -1.08 to 0.78$)$ and central nervous system (CNS) activity ( -1 to 0$)$, they were also found to pass through the $\mathrm{BBB}$, which restrains drug entry from blood into brain by multiple mechanisms [36,37]. Solvent accessible surface area (SASA) is used to define the accessibility of the residue to the solvent; either it is between lipid or water accessibility, and it is essential to BBB permeability [38]. The SASA values of all the compounds were found within the range (467-680). The results also indicated that all the compounds obey Lipinski's rule of five and Jorgensen's rule of 
three; due to the fact that a potential orally active drug candidate should reveal no more than one violation of these rules $[39,40]$.

Table 3. Predicted ADME properties of compounds 1, 2, 3a-i, and 4a-i.

\begin{tabular}{|c|c|c|c|c|c|c|}
\hline Compound & $\begin{array}{l}\text { QplogBB * } \\
(-3 \text { to } 1.2)\end{array}$ & $\begin{array}{c}\text { CNS * } \\
(-2 \text { to } 2)\end{array}$ & $\begin{array}{l}\text { SASA * } \\
(300.0 \text { to } \\
1000.0)\end{array}$ & $\begin{array}{l}\text { Human Oral } \\
\text { Absorption } \% \text { * } \\
\text { (>80\% Is High, } \\
<25 \% \text { Is poor) }\end{array}$ & $\begin{array}{c}\text { Rule } \\
\text { of Five } \\
* *\end{array}$ & $\begin{array}{c}\text { Rule of } \\
\text { Three }\end{array}$ \\
\hline 1 & -0.12 & 0 & 482 & 100 & 0 & 0 \\
\hline 2 & 0.02 & 1 & 467 & 100 & 0 & 0 \\
\hline $3 a$ & 0.49 & 2 & 594 & 100 & 1 & 1 \\
\hline $3 b$ & -0.31 & 0 & 632 & 100 & 0 & 1 \\
\hline $3 c$ & 0.60 & 2 & 603 & 100 & 1 & 1 \\
\hline $3 d$ & 0.66 & 2 & 618 & 100 & 1 & 1 \\
\hline $3 e$ & 0.67 & 2 & 623 & 100 & 1 & 1 \\
\hline $3 f$ & 0.48 & 2 & 626 & 100 & 1 & 1 \\
\hline $3 g$ & 0.42 & 1 & 631 & 100 & 1 & 1 \\
\hline $3 \mathrm{~h}$ & -0.40 & 0 & 680 & 100 & 0 & 1 \\
\hline $3 \mathbf{i}$ & -1.08 & -2 & 666 & 93 & 0 & 1 \\
\hline $4 a$ & 0.59 & 2 & 582 & 100 & 1 & 1 \\
\hline $4 b$ & -0.16 & 0 & 620 & 100 & 0 & 1 \\
\hline $4 c$ & 0.71 & 2 & 591 & 100 & 1 & 1 \\
\hline $4 d$ & 0.77 & 2 & 606 & 100 & 1 & 1 \\
\hline $4 e$ & 0.78 & 2 & 611 & 100 & 1 & 1 \\
\hline $4 f$ & 0.59 & 2 & 614 & 100 & 1 & 1 \\
\hline $4 g$ & 0.53 & 2 & 619 & 100 & 1 & 1 \\
\hline $4 \mathrm{~h}$ & -0.26 & 0 & 669 & 100 & 0 & 0 \\
\hline $4 i$ & -0.91 & -1 & 654 & 92 & 0 & 0 \\
\hline
\end{tabular}

${ }^{*}$ QPlogBB: brain/blood partition coefficient, CNS: predicted central nervous system activity, SASA: total solvent accessible surface area, in square angstroms using a probe with a 1.4 A Radius, and Percent Human Oral Absorption: human oral absorption on a $0-100 \%$ scale. ** Rule of Five: Number of violations of Lipinski's rule of five. The rules are as follows: mol_MW (molecular weight of the molecule) $<500$, QPlogPo/w (predicted octanol/water partition coefficient) $<5$, donorHB (hydrogen-bond donor atoms) $\leq 5$, and accptHB (hydrogen-bond acceptor atoms) $\leq 10$. Compounds that provide these rules are considered as drug-like molecules. *** Rule of Three: Number of violations of Jorgensen's rule of three. The three rules are as follows: QPlogS (predicted aqueous solubility) $>-5.7$, QPPCaco (predicted apparent Caco-2 cell permeability in $\mathrm{nm} / \mathrm{s}$ ) $>22 \mathrm{~nm} / \mathrm{s}$, Primary Metabolites $<7$. Compounds with fewer (and preferably no) violations of these rules are more likely to be orally available (Schrödinger Release 2016-2: QikProp, Schrödinger, LLC, New York, NY, 2016).

\section{Materials and Methods}

\subsection{Chemistry}

All reagents were purchased from commercial suppliers and were used without further purification. Melting points (M.p.) were determined on an Electrothermal 9100 melting point apparatus (Weiss-Gallenkamp, Loughborough, UK) and are uncorrected. IR spectra were recorded on an IRPrestige-21 Fourier Transform Infrared spectrophotometer (Shimadzu, Tokyo, Japan). ${ }^{1} \mathrm{H}$ NMR and ${ }^{13} \mathrm{C}$ NMR spectra were recorded by a Bruker digital FT-NMR spectrometer (Bruker Bioscience, Billerica, MA, USA) in DMSO- $d_{6}$. Mass spectra were recorded on an Agilent LC-MSD-Trap-SL Mass spectrometer (Agilent Technologies, Palo Alto, CA, USA). Elemental analyses were performed on a Perkin Elmer EAL 240 elemental analyzer (Perkin-Elmer, Norwalk, CT, USA) and the results were within $\pm 0.4 \%$ of the theoretical values. Thin Layer Chromatography (TLC) was performed on TLC Silica gel 60 F254 aluminium sheets (Merck, Darmstadt, Germany) to check the purity of the compounds. 
3.1.1. General Procedure for the Synthesis of the Compounds

1-(2-Furanyl/thienyl)-3-aryl-2-propen-1-one (1, 2)

2-Acetylfuran/2-acetylthiophene (0.02 mol), proper aromatic aldehyde (0.02 mol) and 40\% $(w / v)$ sodium hydroxide $(5 \mathrm{~mL})$ in ethanol $(30 \mathrm{~mL})$ were stirred at room temperature for $24 \mathrm{~h}$. Then, the reaction mixture was poured into ice and the precipitated solid was filtered, washed with water, and dried. The product was crystallized from ethanol [29-34].

1-(2-Furanyl)-3-aryl-2-propen-1-one (1). Yield: 55\%. M.p.: 111-113 ${ }^{\circ}$ C. Lit. M.p.: 96-98 ${ }^{\circ} \mathrm{C}$ [41]. IR v $v_{\max }$ $\left(\mathrm{cm}^{-1}\right)$ : 3126.61 (aromatic C-H stretching), 2927.94 (aliphatic C-H stretching), 1651.07 (C=O stretching), 1597.06, 1558.48, 1512.19, 1462.04 (C=C stretching), 1411.89, 1392.61, 1332.81, 1300.02, 1288.45, 1247.94, 1207.44, 1182.36, 1161.15, 1083.99, 1053.13, 1010.70 (C-O stretching and aromatic C-H in plane bending), 981.77, 927.76, 883.40, 864.11, 842.89, 813.96, 802.39, 765.74, 727.16 (aromatic C-H out of plane bending). ${ }^{1} \mathrm{H}-\mathrm{NMR}\left(300 \mathrm{MHz}, \mathrm{DMSO}-d_{6}\right) \delta(\mathrm{ppm}): 2.35\left(3 \mathrm{H}, \mathrm{s}, \mathrm{CH}_{3}\right), 6.79(1 \mathrm{H}, \mathrm{dd}, J=3.57 \mathrm{~Hz}, 1.71 \mathrm{~Hz}$ aromatic proton), $7.28\left(2 \mathrm{H}, \mathrm{d}, J=7.92 \mathrm{~Hz}\right.$, aromatic protons), $7.65\left(1 \mathrm{H}, \mathrm{d}, J=15.72 \mathrm{~Hz}, \mathrm{C}_{3}-\mathrm{H}\right), 7.70(1 \mathrm{H}, \mathrm{d}$, $J=8.76 \mathrm{~Hz}$, aromatic proton), $7.74-7.76\left(2 \mathrm{H}, \mathrm{m}, \mathrm{C}_{2}-\mathrm{H}\right.$ and aromatic proton), $7.81(1 \mathrm{H}, \mathrm{dd}, J=3.60 \mathrm{~Hz}$, $0.63 \mathrm{~Hz}$, aromatic proton), $8.07\left(1 \mathrm{H}, \mathrm{dd}, J=1.65 \mathrm{~Hz}, 0.66 \mathrm{~Hz}\right.$, aromatic proton). ${ }^{13} \mathrm{C}-\mathrm{NMR}(75 \mathrm{MHz}$, DMSO-d $\left.{ }_{6}\right) \delta(\mathrm{ppm}): 21.54\left(\mathrm{CH}_{3}\right), 113.16(\mathrm{CH}), 119.79(\mathrm{CH}), 121.37\left(\mathrm{C}_{2}-\mathrm{H}\right), 129.52(2 \mathrm{CH}), 130.03(2 \mathrm{CH})$, $132.19(\mathrm{C}), 141.20(\mathrm{C}), 143.30\left(\mathrm{C}_{3}-\mathrm{H}\right), 148.74(\mathrm{CH}), 153.46(\mathrm{C}), 177.15(\mathrm{C}, \mathrm{C}=\mathrm{O})$. Anal. Calcd. for $\mathrm{C}_{14} \mathrm{H}_{12} \mathrm{O}_{3}$ : C, 79.22; H, 5.70; Found: C, 79.12; H, 5.64. MS (ESI) $(m / z):[\mathrm{M}+\mathrm{H}]^{+} 212.08$.

1-(2-Thienyl)-3-aryl-2-propen-1-one (2). Yield: 60\%. M.p.: 126-128 ${ }^{\circ}$ C. Lit. M.p.: 117-119 ${ }^{\circ} \mathrm{C}$ [35,42]. IR $v_{\max }\left(\mathrm{cm}^{-1}\right)$ : 3105.39 (aromatic C-H stretching), 2989.66, 2906.73 (aliphatic C-H stretching), 1643.55 (C=O stretching), 1604.77, 1583.56, 1498.69, 1487.12, 1444.68 (C=C stretching), 1411.89, 1369.46, 1346.31, 1305.81, 1246.02, 1228.66, 1215.15, 1192.01, 1105.21, 1058.92, 1028.06 (C-O stretching and aromatic C-H in plane bending), 972.12, 925.83, 916.19, 860.25, 831.32, 800.46, 727.16, 700.16 (aromatic C-H out of plane bending and C-S stretching). ${ }^{1} \mathrm{H}-\mathrm{NMR}\left(300 \mathrm{MHz}, \mathrm{DMSO}-d_{6}\right) \delta$ (ppm): $6.12\left(2 \mathrm{H}, \mathrm{s}, \mathrm{O}-\mathrm{CH}_{2}-\mathrm{O}\right)$, $7.00\left(1 \mathrm{H}, \mathrm{d}, J=8.01 \mathrm{~Hz}\right.$, aromatic proton), 7.30-7.36 (2H, m, aromatic protons), 7.64-7.69 (2H, m, $\mathrm{C}_{2}-\mathrm{H}$ and aromatic protons), $7.76\left(1 \mathrm{H}, \mathrm{d}, J=15.51 \mathrm{~Hz}, \mathrm{C}_{3}-\mathrm{H}\right), 8.04(1 \mathrm{H}, \mathrm{dd}, J=4.92 \mathrm{~Hz}, 0.99 \mathrm{~Hz}$, aromatic proton), $8.32\left(1 \mathrm{H}, \mathrm{dd}, J=3.78 \mathrm{~Hz}, 0.99 \mathrm{~Hz}\right.$, aromatic proton). ${ }^{13} \mathrm{C}-\mathrm{NMR}\left(75 \mathrm{MHz}, \mathrm{DMSO}-d_{6}\right) \delta(\mathrm{ppm})$ : $102.15\left(\mathrm{CH}_{2}\right), 107.42(\mathrm{CH}), 109.01(\mathrm{CH}), 120.35(\mathrm{CH}), 126.46\left(\mathrm{C}_{2}-\mathrm{H}\right), 129.29(\mathrm{CH}), 129.50(\mathrm{C}), 133.83$ $(\mathrm{CH}), 135.70(\mathrm{CH}), 143.61\left(\mathrm{C}_{3}-\mathrm{H}\right), 146.26(\mathrm{C}), 148.58(\mathrm{C}), 150.10(\mathrm{C}), 182.00(\mathrm{C}, \mathrm{C}=\mathrm{O})$. Anal. Calcd. for $\mathrm{C}_{14} \mathrm{H}_{10} \mathrm{O}_{3} \mathrm{~S}: \mathrm{C}, 65.10 ; \mathrm{H}, 3.90$; Found: $\mathrm{C}, 64.98 ; \mathrm{H}, 3.84 . \mathrm{MS}(\mathrm{ESI})(\mathrm{m} / \mathrm{z}):[\mathrm{M}+\mathrm{H}]^{+} 258.04$.

1-(Phenyl/4-Substituted phenyl)-3-(2-furanyl/thienyl)-5-aryl-2-pyrazolines (3a-i, 4a-i)

A mixture of appropriate chalcone $(\mathbf{1}, \mathbf{2})(10.0 \mathrm{mmol})$ and phenylhydrazine hydrochloride derivative $(20.0 \mathrm{mmol})$ was refluxed for $8 \mathrm{~h}$ in absolute ethanol $(30 \mathrm{~mL})$ in the presence of acetic acid $(10 \mathrm{~mL})$ to get 2-pyrazolines. Then the reaction mixture was poured into crushed ice. The precipitate was separated by filtration, washed with water and crystallized from methanol [33].

1-Phenyl-3-(2-furanyl)-5-(4-methylphenyl)-2-pyrazoline (3a) [43]. Yield: 67\%. M.p.: 162-163 ${ }^{\circ} \mathrm{C}$. IR $v_{\max }$ $\left(\mathrm{cm}^{-1}\right)$ : 3113.11, 3034.03 (aromatic C-H stretching), 2918.30, 2848.86 (aliphatic C-H stretching), 1595.13, $1498.69,1487.12$ ( $\mathrm{C}=\mathrm{N}$ and $\mathrm{C}=\mathrm{C}$ stretching), 1413.82, 1365.60, 1334.74, 1319.31, 1247.94, 1176.58, 1128.36, 1072.42, 1051.20, 1033.85, 1022.27 (C-N, C-O stretching and aromatic C-H in plane bending), 997.20, $960.55,923.90,885.33,869.90,842.89,813.96,744.52,731.02,690.52,673.16$ (aromatic C-H out of plane bending). ${ }^{1} \mathrm{H}-\mathrm{NMR}\left(300 \mathrm{MHz}, \mathrm{DMSO}-d_{6}\right) \delta(\mathrm{ppm}): 2.25\left(3 \mathrm{H}, \mathrm{s}, \mathrm{CH}_{3}\right), 2.98\left(1 \mathrm{H}, \mathrm{dd}, J_{A M}=17.28 \mathrm{~Hz}\right.$, $J_{A X}=6.15 \mathrm{~Hz}, \mathrm{C}_{4}-\mathrm{H}_{\mathrm{A}}$ pyrazoline $), 3.82\left(1 \mathrm{H}, \mathrm{dd}, J_{M A}=17.28 \mathrm{~Hz}, J_{M X}=12.12 \mathrm{~Hz}, \mathrm{C}_{4}-\mathrm{H}_{\mathrm{M}}\right.$ pyrazoline), $5.40\left(1 \mathrm{H}, \mathrm{dd}, J_{M X}=12.09 \mathrm{~Hz}, J_{A X}=6.12 \mathrm{~Hz}, \mathrm{C}_{5}-\mathrm{H}_{X}\right.$ pyrazoline $), 6.61(1 \mathrm{H}, \mathrm{dd}, J=3.42 \mathrm{~Hz}, 1.80 \mathrm{~Hz}$, aromatic proton), 6.68-6.77 $(2 \mathrm{H}, \mathrm{m}$, aromatic protons), $6.95(2 \mathrm{H}, \mathrm{d}, J=8.72 \mathrm{~Hz}$, aromatic protons), 7.10-7.16 (6H, m, aromatic protons), $7.80(1 \mathrm{H}, \mathrm{dd}, J=1.71 \mathrm{~Hz}, 0.63 \mathrm{~Hz}) .{ }^{13} \mathrm{C}-\mathrm{NMR}\left(75 \mathrm{MHz}, \mathrm{DMSO}-d_{6}\right)$ $\delta$ (ppm): $22.11\left(\mathrm{CH}_{3}\right), 43.39\left(\mathrm{CH}_{2}\right), 62.85(\mathrm{CH}), 111.12(\mathrm{CH}), 112.42(\mathrm{CH}), 113.45(2 \mathrm{CH}), 119.05(\mathrm{CH})$, $126.22(2 \mathrm{CH}), 129.30(2 \mathrm{CH}), 129.66(\mathrm{C}), 130.01(2 \mathrm{CH}), 137.08(\mathrm{CH}), 139.66(\mathrm{C}, \mathrm{d}, J=3.75 \mathrm{~Hz}), 144.62(2 \mathrm{C}$, 
d, $J=6.00 \mathrm{~Hz}), 147.97(\mathrm{C})$. Anal. Calcd. for $\mathrm{C}_{20} \mathrm{H}_{18} \mathrm{~N}_{2} \mathrm{O}: \mathrm{C}, 79.44 ; \mathrm{H}, 6.00 ; \mathrm{N}, 9.26$; Found: $\mathrm{C}, 79.39 ; \mathrm{H}$, 6.04; N, 9.25. MS (ESI) $(m / z):[\mathrm{M}]^{+} 302.00,[\mathrm{M}+\mathrm{H}]^{+} 303.00$.

1-(4-Cyanophenyl)-3-(2-furanyl)-5-(4-methylphenyl)-2-pyrazoline (3b). Yield: 55\%. M.p.: 77-78 ${ }^{\circ} \mathrm{C}$. IR $v_{\max }$ $\left(\mathrm{cm}^{-1}\right.$ ): 3118.90 (aromatic $\mathrm{C}-\mathrm{H}$ stretching), 2918.30 (aliphatic $\mathrm{C}-\mathrm{H}$ stretching), 2212.35 (C $\equiv \mathrm{N}$ stretching), $1598.99,1510.26$ ( $C=\mathrm{N}$ and $\mathrm{C}=\mathrm{C}$ stretching), 1415.75, 1373.32, 1323.17, 1174.65, 1122.57, 1004.91 (C-N, $\mathrm{C}-\mathrm{O}$ stretching and aromatic $\mathrm{C}-\mathrm{H}$ in plane bending), 812.03, 740.67 (aromatic $\mathrm{C}-\mathrm{H}$ out of plane bending). ${ }^{1} \mathrm{H}-\mathrm{NMR}\left(300 \mathrm{MHz}, \mathrm{DMSO}-d_{6}\right) \delta(\mathrm{ppm}): 2.25\left(3 \mathrm{H}, \mathrm{s}, \mathrm{CH}_{3}\right), 3.06\left(1 \mathrm{H}, \mathrm{dd}, J_{A M}=17.58 \mathrm{~Hz}, J_{A X}=4.65 \mathrm{~Hz}\right.$, $\mathrm{C}_{4}-\mathrm{H}_{\mathrm{A}}$ pyrazoline), $3.90\left(1 \mathrm{H}, \mathrm{dd}, J_{M A}=17.49 \mathrm{~Hz}, J_{M X}=11.91 \mathrm{~Hz}, \mathrm{C}_{4}-\mathrm{H}_{\mathrm{M}}\right.$ pyrazoline $), 5.58(1 \mathrm{H}, \mathrm{dd}$, $J_{M X}=11.76 \mathrm{~Hz}, J_{A X}=4.68 \mathrm{~Hz}, \mathrm{C}_{5}-\mathrm{H}_{X}$ pyrazoline $), 6.64-6.65(1 \mathrm{H}, \mathrm{m}$, aromatic proton $), 6.90(1 \mathrm{H}, \mathrm{d}$, $J=3.30 \mathrm{~Hz}$, aromatic proton), $7.01(2 \mathrm{H}, \mathrm{d}, J=8.73 \mathrm{~Hz}$, aromatic protons), 7.07-7.16 $(4 \mathrm{H}, \mathrm{m}$, aromatic protons), $7.54\left(2 \mathrm{H}, \mathrm{d}, J=8.73 \mathrm{~Hz}\right.$, aromatic protons), $7.86\left(1 \mathrm{H}, \mathrm{s}\right.$, aromatic proton). ${ }^{13} \mathrm{C}-\mathrm{NMR}(75 \mathrm{MHz}$, DMSO- $\left.d_{6}\right) \delta$ (ppm): $21.10\left(\mathrm{CH}_{3}\right), 43.44\left(\mathrm{CH}_{2}\right), 61.91(\mathrm{CH}), 99.40(\mathrm{C}), 112.66(\mathrm{CH}), 112.98(\mathrm{CH}), 113.25$ $(2 \mathrm{CH}), 120.39(\mathrm{C}), 126.04(2 \mathrm{CH}), 130.19(2 \mathrm{CH}), 133.76(2 \mathrm{CH}), 137.50(\mathrm{C}), 138.56(\mathrm{C}), 142.89(2 \mathrm{C}), 145.53$ $(\mathrm{CH}), 146.89$ (C). Anal. Calcd. for $\mathrm{C}_{21} \mathrm{H}_{17} \mathrm{~N}_{3} \mathrm{O}: \mathrm{C}, 77.04 ; \mathrm{H}, 5.23 ; \mathrm{N}, 12.84$; Found: $\mathrm{C}, 77.06 ; \mathrm{H}, 5.24 ; \mathrm{N}$, 12.82. MS (ESI) $(m / z):[\mathrm{M}+\mathrm{H}]^{+} 327.90$.

1-(4-Fluorophenyl)-3-(2-furanyl)-5-(4-methylphenyl)-2-pyrazoline (3c). Yield: 53\%. M.p.: 87-89 ${ }^{\circ} \mathrm{C}$. IR $v_{\max }$ ( $\mathrm{cm}^{-1}$ ): 2987.74, 2900.94 (aliphatic C-H stretching), 1597.06, 1508.33 ( $\mathrm{C}=\mathrm{N}$ and C=C stretching), 1413.82, $1373.32,1321.24,1172.72,1002.98$ (C-N, C-O stretching and aromatic C-H in plane bending), 812.03, 742.59 (aromatic C-H out of plane bending). ${ }^{1} \mathrm{H}-\mathrm{NMR}\left(300 \mathrm{MHz}, \mathrm{DMSO}-d_{6}\right) \delta(\mathrm{ppm}): 2.25(3 \mathrm{H}, \mathrm{s}$, $\left.\mathrm{CH}_{3}\right), 2.98\left(1 \mathrm{H}, \mathrm{dd}, J_{A M}=17.25 \mathrm{~Hz}, J_{A X}=6.57 \mathrm{~Hz}, \mathrm{C}_{4}-\mathrm{H}_{\mathrm{A}}\right.$ pyrazoline $), 3.82\left(1 \mathrm{H}, \mathrm{dd}, J_{M A}=17.25 \mathrm{~Hz}\right.$, $J_{M X}=12.03 \mathrm{~Hz}, \mathrm{C}_{4}-\mathrm{H}_{\mathrm{M}}$ pyrazoline), $5.37\left(1 \mathrm{H}, \mathrm{dd}, J_{M X}=11.97 \mathrm{~Hz}, J_{A X}=6.54 \mathrm{~Hz}, \mathrm{C}_{5}-\mathrm{H}_{X}\right.$ pyrazoline), $6.61(1 \mathrm{H}, \mathrm{dd}, J=3.36 \mathrm{~Hz}, 1.77 \mathrm{~Hz}$, aromatic proton), $6.76(1 \mathrm{H}, \mathrm{d}, J=3.33 \mathrm{~Hz}$, aromatic proton), 6.93-6.99 $(4 \mathrm{H}, \mathrm{m}$, aromatic protons), $7.15(4 \mathrm{H}, \mathrm{s}$, aromatic protons $), 7.80(1 \mathrm{H}, \mathrm{d}, \mathrm{J}=1.44 \mathrm{~Hz}$, aromatic proton). ${ }^{13} \mathrm{C}-\mathrm{NMR}\left(75 \mathrm{MHz}, \mathrm{DMSO}-d_{6}\right) \delta(\mathrm{ppm}): 21.09\left(\mathrm{CH}_{3}\right), 43.57\left(\mathrm{CH}_{2}\right), 63.42(\mathrm{CH}), 111.20(\mathrm{CH}), 112.43(\mathrm{CH})$, $114.65(\mathrm{CH}, \mathrm{d}, J=7.5 \mathrm{~Hz}), 115.84(\mathrm{CH}, \mathrm{d}, J=22.5 \mathrm{~Hz}), 126.32(2 \mathrm{CH}), 130.04(2 \mathrm{CH}), 137.18(\mathrm{CH}), 139.36$ (CH), $139.93(\mathrm{C}), 141.56(\mathrm{C}), 144.70(\mathrm{CH}), 147.56(\mathrm{C}), 147.88$ (C), $154.79(\mathrm{C}), 157.90(\mathrm{C})$. Anal. Calcd. for $\mathrm{C}_{20} \mathrm{H}_{17} \mathrm{FN}_{2} \mathrm{O}: \mathrm{C}, 74.98 ; \mathrm{H}, 5.35 ; \mathrm{N}, 8.74$; Found: $\mathrm{C}, 74.94 ; \mathrm{H}, 5.33 ; \mathrm{N}, 8.76$. MS (ESI) $(m / z):[\mathrm{M}+\mathrm{H}]^{-}$ 318.90, $[\mathrm{M}]^{+}$320.90, $[\mathrm{M}+\mathrm{H}]^{+} 321.90$.

1-(4-Chlorophenyl)-3-(2-furanyl)-5-(4-methylphenyl)-2-pyrazoline (3d). Yield: 83\%. M.p.: $115-117^{\circ} \mathrm{C}$. IR $v_{\max }\left(\mathrm{cm}^{-1}\right)$ : 2987.74, 2900.94 (aliphatic C-H stretching), 1598.99, 1492.90 (C=N and C=C stretching), $1375.25,1076.28,1051.20$ (C-N, C-O stretching and aromatic C-H in plane bending), 817.82, 734.88 (aromatic C-H out of plane bending). ${ }^{1} \mathrm{H}-\mathrm{NMR}\left(300 \mathrm{MHz}, \mathrm{DMSO}-d_{6}\right) \delta$ (ppm): $2.25\left(3 \mathrm{H}, \mathrm{s}, \mathrm{CH}_{3}\right), 3.00$ $\left(1 \mathrm{H}, \mathrm{dd}, J_{A M}=17.37 \mathrm{~Hz}, J_{A X}=5.85 \mathrm{~Hz}, \mathrm{C}_{4}-\mathrm{H}_{\mathrm{A}}\right.$ pyrazoline $), 3.84\left(1 \mathrm{H}, \mathrm{dd}, J_{M A}=17.37 \mathrm{~Hz}, J_{M X}=12.06 \mathrm{~Hz}\right.$, $\mathrm{C}_{4}-\mathrm{H}_{\mathrm{M}}$ pyrazoline), $5.43\left(1 \mathrm{H}, \mathrm{dd}, J_{M X}=12.06 \mathrm{~Hz}, J_{A X}=5.82 \mathrm{~Hz}, \mathrm{C}_{5}-\mathrm{H}_{X}\right.$ pyrazoline $), 6.61(1 \mathrm{H}, \mathrm{dd}$, $J=3.45 \mathrm{~Hz}, 1.80 \mathrm{~Hz}$, aromatic proton), $6.79(1 \mathrm{H}, \mathrm{d}, J=3.93 \mathrm{~Hz}$, aromatic proton), $6.93(2 \mathrm{H}, \mathrm{d}, J=7.94 \mathrm{~Hz}$, aromatic protons), $7.13(4 \mathrm{H}, \mathrm{s}$, aromatic protons), $7.17(2 \mathrm{H}, \mathrm{d}, J=9.00 \mathrm{~Hz}$, aromatic protons $), 7.81(1 \mathrm{H}$, $\mathrm{dd}, J=1.68 \mathrm{~Hz}, 0.63 \mathrm{~Hz}$, aromatic proton). ${ }^{13} \mathrm{C}-\mathrm{NMR}\left(75 \mathrm{MHz}, \mathrm{DMSO}-d_{6}\right) \delta(\mathrm{ppm}): 21.08\left(\mathrm{CH}_{3}\right), 43.49$ $\left(\mathrm{CH}_{2}\right), 62.75(\mathrm{CH}), 111.60(\mathrm{CH}), 112.48(\mathrm{CH}), 114.85(2 \mathrm{CH}), 122.60(\mathrm{C}), 126.20(2 \mathrm{CH}), 129.11(2 \mathrm{CH})$, $130.07(2 \mathrm{CH}), 137.23(\mathrm{C}), 139.11(\mathrm{C}), 140.51(\mathrm{C}), 143.36(\mathrm{C}), 144.89(\mathrm{CH}), 147.73(\mathrm{C})$. Anal. Calcd. for $\mathrm{C}_{20} \mathrm{H}_{17} \mathrm{ClN}_{2} \mathrm{O}: \mathrm{C}, 71.32 ; \mathrm{H}, 5.09 ; \mathrm{N}, 8.32$; Found: $\mathrm{C}, 71.28 ; \mathrm{H}, 5.03 ; \mathrm{N}, 8.35$. MS (ESI) $(\mathrm{m} / \mathrm{z}):[\mathrm{M}+\mathrm{H}]^{--}$ 334.90, $[\mathrm{M}]^{+}$336.90, $[\mathrm{M}+\mathrm{H}]^{+} 337.90$.

1-(4-Bromophenyl)-3-(2-furanyl)-5-(4-methylphenyl)-2-pyrazoline (3e). Yield: 79\%. M.p.: 133-135 ${ }^{\circ} \mathrm{C}$. IR $v_{\max }\left(\mathrm{cm}^{-1}\right): 2999.31,2920.23$ (aliphatic C-H stretching), 1593.20, 1512.19, 1492.90, $1483.26(\mathrm{C}=\mathrm{N}$ and $C=C$ stretching), 1365.60, 1319.31, 1122.57, 1087.85, 1074.35, 1051.20, 1004.91 (C-N, C-O stretching and aromatic C-H in plane bending), 883.40, 862.18, 815.89, 792.74, 732.95 (aromatic C-H out of plane bending). ${ }^{1} \mathrm{H}-\mathrm{NMR}\left(300 \mathrm{MHz}, \mathrm{DMSO}-d_{6}\right) \delta(\mathrm{ppm}): 2.25\left(3 \mathrm{H}, \mathrm{s}, \mathrm{CH}_{3}\right), 3.00\left(1 \mathrm{H}, \mathrm{dd}, J_{A M}=17.37 \mathrm{~Hz}\right.$, $J_{A X}=5.76 \mathrm{~Hz}, \mathrm{C}_{4}-\mathrm{H}_{\mathrm{A}}$ pyrazoline $), 3.83\left(1 \mathrm{H}, \mathrm{dd}, J_{M A}=17.34 \mathrm{~Hz}, J_{M X}=12.06 \mathrm{~Hz}, \mathrm{C}_{4}-\mathrm{H}_{\mathrm{M}}\right.$ pyrazoline), $5.43\left(1 \mathrm{H}, \mathrm{dd}, J_{M X}=12.03 \mathrm{~Hz}, J_{A X}=5.70 \mathrm{~Hz}, \mathrm{C}_{5}-\mathrm{H}_{X}\right.$ pyrazoline $), 6.61(1 \mathrm{H}, \mathrm{dd}, J=3.42 \mathrm{~Hz}, 1.80 \mathrm{~Hz}$, 
aromatic proton), $6.79(1 \mathrm{H}, \mathrm{d}, J=3.39 \mathrm{~Hz}$, aromatic proton), $6.88(2 \mathrm{H}, \mathrm{d}, J=9.00 \mathrm{~Hz}$, aromatic protons), $7.12(4 \mathrm{H}, \mathrm{s}$, aromatic protons), $7.29(2 \mathrm{H}, \mathrm{d}, J=8.97 \mathrm{~Hz}$, aromatic protons), $7.81(1 \mathrm{H}, \mathrm{t}, J=1.65 \mathrm{~Hz}, 1.08 \mathrm{~Hz}$, $0.57 \mathrm{~Hz}$, aromatic proton). ${ }^{13} \mathrm{C}-\mathrm{NMR}\left(75 \mathrm{MHz}, \mathrm{DMSO}-d_{6}\right) \delta$ (ppm): $21.09\left(\mathrm{CH}_{3}\right), 43.48\left(\mathrm{CH}_{2}\right), 62.64$ $(\mathrm{CH}), 110.21(\mathrm{C}), 111.65(\mathrm{CH}), 112.49(\mathrm{CH}), 115.35(2 \mathrm{CH}), 126.19(2 \mathrm{CH}), 130.07(2 \mathrm{CH}), 131.94(2 \mathrm{CH})$, 137.24 (C), 139.05 (C), 140.57 (C), 143.67 (C), $144.91(\mathrm{CH}), 147.72(\mathrm{C})$. Anal. Calcd. for $\mathrm{C}_{20} \mathrm{H}_{17} \mathrm{BrN}_{2} \mathrm{O}: \mathrm{C}_{\text {, }}$ 63.00; H, 4.49; N, 7.35; Found: C, 63.04; H, 4.53; N, 7.32. MS (ESI) $(m / z):[\mathrm{M}+\mathrm{H}]^{--} 378.80,[\mathrm{M}]^{+}$380.80, $[\mathrm{M}+\mathrm{H}]^{+}$381.90, $[\mathrm{M}+\mathrm{H}]^{+++} 383.00$.

1-(4-Methylphenyl)-3-(2-furanyl)-5-(4-methylphenyl)-2-pyrazoline (3f). Yield: 53\%; M.p. 67-68 ${ }^{\circ} \mathrm{C}$. IR $v_{\max }$ $\left(\mathrm{cm}^{-1}\right)$ : 2972.31, 2900.94 (aliphatic C-H stretching), 1614.42, 1512.19 (C=N and C=C stretching), 1408.04, $1365.60,1249.87,1074.35,1049.28$ (C-N, C-O stretching and aromatic C-H in plane bending), 883.40, 804.32, 738.74 (aromatic C-H out of plane bending). ${ }^{1} \mathrm{H}-\mathrm{NMR}\left(300 \mathrm{MHz}, \mathrm{DMSO}-d_{6}\right) \delta(\mathrm{ppm}): 2.15(3 \mathrm{H}$, $\left.\mathrm{s}, \mathrm{CH}_{3}\right), 2.24\left(3 \mathrm{H}, \mathrm{s}, \mathrm{CH}_{3}\right), 2.95\left(1 \mathrm{H}, \mathrm{dd}, J_{A M}=17.19 \mathrm{~Hz}, J_{A X}=6.36 \mathrm{~Hz}, \mathrm{C}_{4}-\mathrm{H}_{\mathrm{A}}\right.$ pyrazoline $), 3.79(1 \mathrm{H}, \mathrm{dd}$, $J_{M A}=17.22 \mathrm{~Hz}, J_{M X}=12.09 \mathrm{~Hz}, \mathrm{C}_{4}-\mathrm{H}_{\mathrm{M}}$ pyrazoline $), 5.36\left(1 \mathrm{H}, \mathrm{dd}, J_{M X}=12.09 \mathrm{~Hz}, J_{A X}=6.33 \mathrm{~Hz}, \mathrm{C}_{5}-\mathrm{H}_{X}\right.$ pyrazoline), $6.60(1 \mathrm{H}, \mathrm{dd}, J=3.42 \mathrm{~Hz}, 1.80 \mathrm{~Hz}$, aromatic proton), $6.72-6.74(1 \mathrm{H}, \mathrm{m}$, aromatic proton), 6.83-6.86 (2H, m, aromatic protons), $6.94(2 \mathrm{H}, \mathrm{d}, J=8.34 \mathrm{~Hz}$, aromatic protons), 7.09-7.13 (4H, $\mathrm{m}$, aromatic protons), $7.78\left(1 \mathrm{H}, \mathrm{dd}, J=1.71 \mathrm{~Hz}, 0.63 \mathrm{~Hz}\right.$, aromatic proton). ${ }^{13} \mathrm{C}-\mathrm{NMR}\left(75 \mathrm{MHz}, \mathrm{DMSO}-d_{6}\right)$ $\delta$ (ppm): $20.54\left(\mathrm{CH}_{3}\right), 21.08\left(\mathrm{CH}_{3}\right), 43.34\left(\mathrm{CH}_{2}\right), 63.13(\mathrm{CH}), 110.79(\mathrm{CH}), 112.39(\mathrm{CH}), 113.63(2 \mathrm{CH})$, $126.28(2 \mathrm{CH}), 127.76(\mathrm{CH}), 128.80(\mathrm{C}), 129.73(2 \mathrm{CH}, \mathrm{d}, J=16.50 \mathrm{~Hz}), 137.00(\mathrm{C}), 139.16(\mathrm{C}), 139.67(\mathrm{CH})$, $142.51(2 \mathrm{C}), 144.51(\mathrm{CH}), 148.08$ (C). Anal. Calcd. for $\mathrm{C}_{21} \mathrm{H}_{20} \mathrm{~N}_{2} \mathrm{O}$ : C, 79.72; H, 6.37; N, 8.85; Found: C, 79.66; H, 6.28; N, 8.89. MS (ESI) $(m / z):[\mathrm{M}]^{+}$316.90, $[\mathrm{M}+\mathrm{H}]^{+} 318.00$.

1-(4-Methoxyphenyl)-3-(2-furanyl)-5-(4-methylphenyl)-2-pyrazoline (3g). Yield: 27\%; M.p. $70-72{ }^{\circ} \mathrm{C}$. IR $v_{\max }\left(\mathrm{cm}^{-1}\right)$ : 3118.90 (aromatic C-H stretching), 2918.30, 2831.50 (aliphatic C-H stretching), 1606.70, 1568.13, 1506.41, 1463.97 ( $\mathrm{C}=\mathrm{N}$ and $\mathrm{C}=\mathrm{C}$ stretching), 1359.82, 1292.31, 1238.30, 1178.51, 1120.64, 1097.50, 1035.77 (C-N, C-O stretching and aromatic C-H in plane bending), 883.40, 873.75, 815.89, 746.45 (aromatic C-H out of plane bending). ${ }^{1} \mathrm{H}-\mathrm{NMR}\left(300 \mathrm{MHz}, \mathrm{DMSO}-d_{6}\right) \delta$ (ppm): $2.25\left(3 \mathrm{H}, \mathrm{s}, \mathrm{CH}_{3}\right)$, $2.95\left(1 \mathrm{H}, \mathrm{dd}, J_{A M}=17.13 \mathrm{~Hz}, J_{A X}=7.14 \mathrm{~Hz}, \mathrm{C}_{4}-\mathrm{H}_{\mathrm{A}}\right.$ pyrazoline $), 3.63\left(3 \mathrm{H}, \mathrm{s}, \mathrm{OCH}_{3}\right), 3.69(1 \mathrm{H}, \mathrm{dd}$, $J_{M A}=17.18 \mathrm{~Hz}, J_{M X}=12.00 \mathrm{~Hz}, \mathrm{C}_{4}-\mathrm{H}_{\mathrm{M}}$ pyrazoline $), 5.30\left(1 \mathrm{H}, \mathrm{dd}, J_{M X}=11.97 \mathrm{~Hz}, J_{A X}=7.17 \mathrm{~Hz}, \mathrm{C}_{5}-\mathrm{H}_{X}\right.$ pyrazoline), $6.59(1 \mathrm{H}, \mathrm{dd}, J=3.42 \mathrm{~Hz}, 1.80 \mathrm{~Hz}$, aromatic proton), 6.71-6.77 (3H, $\mathrm{m}$, aromatic protons), 6.86-6.90 (2H, m, aromatic protons), 7.12-7.18 (4H, m, aromatic protons), $7.78(1 \mathrm{H}, \mathrm{dd}, J=1.71 \mathrm{~Hz}$, $0.66 \mathrm{~Hz}$, aromatic proton). ${ }^{13} \mathrm{C}-\mathrm{NMR}\left(75 \mathrm{MHz}, \mathrm{DMSO}-d_{6}\right) \delta(\mathrm{ppm}): 21.08\left(\mathrm{CH}_{3}\right), 43.47\left(\mathrm{CH}_{2}\right), 55.63$ $\left(\mathrm{CH}_{3}\right), 63.94(\mathrm{CH}), 106.80(\mathrm{CH}), 110.58(\mathrm{CH}), 112.36(\mathrm{CH}), 114.88(2 \mathrm{CH}, \mathrm{d}, J=12.75 \mathrm{~Hz}), 126.42(2 \mathrm{CH})$, $127.34(\mathrm{C}), 130.01(2 \mathrm{CH}, \mathrm{d}, J=8.25 \mathrm{~Hz}), 137.03(\mathrm{C}), 138.97(\mathrm{C}), 139.16(\mathrm{C}), 139.69(\mathrm{CH}), 144.41(\mathrm{CH})$, 148.14 (C), 153.15 (C). Anal. Calcd. for $\mathrm{C}_{21} \mathrm{H}_{20} \mathrm{~N}_{2} \mathrm{O}_{2}$ : C, 75.88; H, 6.06; N, 8.43; Found: C, 75.90; H, 6.04; $\mathrm{N}$, 8.50. MS (ESI) $(\mathrm{m} / \mathrm{z}):[\mathrm{M}]^{+} 332.00,[\mathrm{M}+\mathrm{H}]^{+} 333.00$.

1-(4-Methylsulfonylphenyl)-3-(2-furanyl)-5-(4-methylphenyl)-2-pyrazoline (3h). Yield: 68\%. M.p.: $162-163^{\circ} \mathrm{C}$. IR $v_{\max }\left(\mathrm{cm}^{-1}\right)$ : 2985.81, 2900.94 (aliphatic C-H stretching), 1589.34, 1506.41 (C=N and C=C stretching), 1406.11, 1379.10, 1292.31, 1242.16, 1132.21, 1066.64 (C-N, C-O stretching and aromatic C-H in plane bending), 960.55, 883.40, 815.89, 769.60 (aromatic C-H out of plane bending and C-S stretching). ${ }^{1} \mathrm{H}-\mathrm{NMR}$ (300 MHz, DMSO- $\left.d_{6}\right) \delta(\mathrm{ppm}): 2.24\left(3 \mathrm{H}, \mathrm{s}, \mathrm{CH}_{3}\right), 3.00\left(1 \mathrm{H}, \mathrm{dd}, J_{A M}=17.37 \mathrm{~Hz}, J_{A X}=5.76 \mathrm{~Hz}, \mathrm{C}_{4}-\mathrm{H}_{\mathrm{A}}\right.$ pyrazoline), $3.06\left(3 \mathrm{H}, \mathrm{s}, \mathrm{SO}_{2} \mathrm{CH}_{3}\right), 3.91\left(1 \mathrm{H}, \mathrm{dd}, J_{M A}=17.55 \mathrm{~Hz}, J_{M X}=11.97 \mathrm{~Hz}, \mathrm{C}_{4}-\mathrm{H}_{\mathrm{M}}\right.$ pyrazoline $), 5.59$ $\left(1 \mathrm{H}, \mathrm{dd}, J_{M X}=11.88 \mathrm{~Hz}, J_{A X}=4.74 \mathrm{~Hz}, \mathrm{C}_{5}-\mathrm{H}_{X}\right.$ pyrazoline $), 6.64(1 \mathrm{H}, \mathrm{dd}, \mathrm{J}=3.39 \mathrm{~Hz}, 1.77 \mathrm{~Hz}$, aromatic proton), $6.89(1 \mathrm{H}, \mathrm{d}, J=3.39 \mathrm{~Hz}$, aromatic proton), $7.07(2 \mathrm{H}, \mathrm{d}, J=8.88 \mathrm{~Hz}$, aromatic protons), $7.14(4 \mathrm{H}, \mathrm{s}$, aromatic protons), $7.65(2 \mathrm{H}, \mathrm{d}, J=8.97 \mathrm{~Hz}$, aromatic protons $), 7.86(1 \mathrm{H}, \mathrm{t}, J=1.59 \mathrm{~Hz}, 1.20 \mathrm{~Hz}, 0.39 \mathrm{~Hz}$, aromatic proton). ${ }^{13} \mathrm{C}-\mathrm{NMR}\left(75 \mathrm{MHz}, \mathrm{DMSO}-d_{6}\right) \delta(\mathrm{ppm}): 21.10\left(\mathrm{CH}_{3}\right), 43.45\left(\mathrm{CH}_{2}\right), 44.62\left(\mathrm{CH}_{3}\right), 61.98$ $(\mathrm{CH}), 112.76(2 \mathrm{CH}, \mathrm{d}, J=18.75 \mathrm{~Hz}), 113.67(\mathrm{CH}), 126.06(2 \mathrm{CH}), 129.02(2 \mathrm{CH}), 129.55(\mathrm{CH}), 129.85(\mathrm{C})$, $130.20(2 \mathrm{CH}), 137.46(\mathrm{C}), 139.63(\mathrm{C}), 142.64(\mathrm{C}), 145.45(\mathrm{CH}), 147.35(2 \mathrm{C}, \mathrm{d}, J=8.25 \mathrm{~Hz})$. Anal. Calcd. for $\mathrm{C}_{21} \mathrm{H}_{20} \mathrm{~N}_{2} \mathrm{O}_{3} \mathrm{~S}: \mathrm{C}, 66.29 ; \mathrm{H}, 5.30 ; \mathrm{N}, 7.36$; Found: C, 66.26; H, 5.34; N, 7.39. MS (ESI) (m/z): [M] ${ }^{+}$380.90, $[\mathrm{M}+\mathrm{H}]^{+} 382.00$. 
1-(4-Sulfonamidophenyl)-3-(2-furanyl)-5-(4-methylphenyl)-2-pyrazoline (3i). Yield: 88\%. M.p.: $139-140{ }^{\circ} \mathrm{C}$. IR $v_{\max }\left(\mathrm{cm}^{-1}\right): 3369.64,3257.77$ (N-H stretching), 3120.82, (aromatic C-H stretching), 2920.23, 2852.72 (aliphatic C-H stretching), 1589.34, 1504.48 (C=N and C=C stretching), 1413.82, 1373.32, 1325.10, 1305.81, 1149.57, 1095.57, 1002.98 (C-N, C-O stretching and aromatic C-H in plane bending), 883.40, 866.04, 815.89, 738.74 (aromatic C-H out of plane bending and C-S stretching). ${ }^{1} \mathrm{H}-\mathrm{NMR}$ (300 MHz, DMSO- $d_{6}$ ) $\delta(\mathrm{ppm}): 2.24\left(3 \mathrm{H}, \mathrm{s}, \mathrm{CH}_{3}\right), 3.05\left(1 \mathrm{H}, \mathrm{dd}, J_{A M}=17.46 \mathrm{~Hz}, J_{A X}=4.92 \mathrm{~Hz}, \mathrm{C}_{4}-\mathrm{H}_{\mathrm{A}}\right.$ pyrazoline $), 3.89(1 \mathrm{H}, \mathrm{dd}$, $J_{M A}=17.49 \mathrm{~Hz}, J_{M X}=12.00 \mathrm{~Hz}, \mathrm{C}_{4}-\mathrm{H}_{M}$ pyrazoline $), 5.57\left(1 \mathrm{H}, \mathrm{dd}, J_{M X}=11.94 \mathrm{~Hz}, J_{A X}=4.83 \mathrm{~Hz}, \mathrm{C}_{5}-\mathrm{H}_{X}\right.$ pyrazoline), $6.63(1 \mathrm{H}, \mathrm{dd}, J=3.45 \mathrm{~Hz}, 1.80 \mathrm{~Hz}$, aromatic proton), $6.85(1 \mathrm{H}, \mathrm{d}, J=3.41 \mathrm{~Hz}$, aromatic proton), 6.99-7.03 $\left(4 \mathrm{H}, \mathrm{m}\right.$, aromatic and $\mathrm{NH}_{2}$ protons $), 7.12-7.13(4 \mathrm{H}, \mathrm{m}$, aromatic protons $), 7.57(2 \mathrm{H}, \mathrm{d}$, $J=8.97 \mathrm{~Hz}$, aromatic protons), $7.84(1 \mathrm{H}, \mathrm{dd}, J=1.71 \mathrm{~Hz}, 0.66 \mathrm{~Hz}) .{ }^{13} \mathrm{C}-\mathrm{NMR}\left(75 \mathrm{MHz}, \mathrm{DMSO}-d_{6}\right) \delta$ (ppm): $21.08\left(\mathrm{CH}_{3}\right), 43.33\left(\mathrm{CH}_{2}\right), 62.06(\mathrm{CH}), 112.48(2 \mathrm{CH}, \mathrm{d}, J=12.00 \mathrm{~Hz}), 126.12(2 \mathrm{CH}), 127.59(2 \mathrm{CH})$, $130.11(2 \mathrm{CH}), 133.51(\mathrm{C}), 137.35(\mathrm{CH}), 138.73(2 \mathrm{CH}), 141.85(\mathrm{C}), 145.24(2 \mathrm{C}), 146.22(\mathrm{C}), 147.47$ (C). Anal. Calcd. for $\mathrm{C}_{20} \mathrm{H}_{19} \mathrm{~N}_{3} \mathrm{O}_{3} \mathrm{~S}: \mathrm{C}, 62.97 ; \mathrm{H}, 5.02 ; \mathrm{N}, 11.02$; Found: C, 62.94; H, 5.03; N, 11.05. MS (ESI) (m/z): $[\mathrm{M}]^{+}$381.90, $[\mathrm{M}+\mathrm{H}]^{+}$382.90.

1-Phenyl-3-(2-thienyl)-5-(1,3-benzodioxol-5-yl)-2-pyrazoline (4a) [44]. Yield: 83\%. M.p.: 179-180 ${ }^{\circ} \mathrm{C}$. IR $v_{\max }\left(\mathrm{cm}^{-1}\right): 3105.39,3070.68$ (aromatic C-H stretching), 2916.37 (aliphatic C-H stretching), 1593.20, $1498.69,1481.33,1442.75$ ( $C=\mathrm{N}$ and $\mathrm{C}=\mathrm{C}$ stretching), 1379.10, 1317.38, 1238.30, 1109.07, 1037.70 (C-N, C-O stretching and aromatic C-H in plane bending), 937.40, 823.60, 748.38, 719.45 (aromatic C-H out of plane bending and C-S stretching). ${ }^{1} \mathrm{H}-\mathrm{NMR}\left(300 \mathrm{MHz}, \mathrm{DMSO}-d_{6}\right) \delta(\mathrm{ppm}): 3.10(1 \mathrm{H}, \mathrm{dd}$, $J_{A M}=17.37 \mathrm{~Hz}, J_{A X}=6.33 \mathrm{~Hz}, \mathrm{C}_{4}-\mathrm{H}_{\mathrm{A}}$ pyrazoline $), 3.87\left(1 \mathrm{H}, \mathrm{dd}, J_{M A}=17.37 \mathrm{~Hz}, J_{M X}=12.09 \mathrm{~Hz}, \mathrm{C}_{4}-\mathrm{H}_{\mathrm{M}}\right.$ pyrazoline), $5.40\left(1 \mathrm{H}, \mathrm{dd}, J_{M X}=12.00 \mathrm{~Hz}, J_{A X}=6.30 \mathrm{~Hz}, \mathrm{C}_{5}-\mathrm{H}_{X}\right.$ pyrazoline $), 5.97(2 \mathrm{H}, \mathrm{d}, J=0.57 \mathrm{~Hz}$, $\left.\mathrm{O}-\mathrm{CH}_{2}-\mathrm{O}\right), 6.70-6.79(3 \mathrm{H}, \mathrm{m}$, aromatic protons $), 6.87(1 \mathrm{H}, \mathrm{d}, J=8.13 \mathrm{~Hz}$, aromatic proton), $6.95(2 \mathrm{H}, \mathrm{d}$, $J=7.89 \mathrm{~Hz}$, aromatic protons), 7.08-7.18 $(3 \mathrm{H}, \mathrm{m}$, aromatic protons $), 7.25(1 \mathrm{H}, \mathrm{d}, J=3.51 \mathrm{~Hz}$, aromatic proton), $7.59\left(1 \mathrm{H}, \mathrm{d}, J=5.04 \mathrm{~Hz}\right.$, aromatic proton). ${ }^{13} \mathrm{C}-\mathrm{NMR}\left(75 \mathrm{MHz}, \mathrm{DMSO}-d_{6}\right) \delta(\mathrm{ppm}): 44.18\left(\mathrm{CH}_{2}\right)$, $63.51(\mathrm{CH}), 101.52\left(\mathrm{CH}_{2}\right), 106.54(\mathrm{CH}), 109.07(\mathrm{CH}), 113.46(2 \mathrm{CH}), 119.16(\mathrm{CH}), 119.57(\mathrm{CH}), 127.90$ $(2 \mathrm{CH}), 128.28(\mathrm{CH}), 129.35(2 \mathrm{CH}), 136.15(\mathrm{C}), 136.59$ (C), $144.21(\mathrm{C}), 144.50(\mathrm{C}), 146.99(\mathrm{C}), 148.19(\mathrm{C})$. Anal. Calcd. for $\mathrm{C}_{20} \mathrm{H}_{16} \mathrm{~N}_{2} \mathrm{O}_{2} \mathrm{~S}$ : C, 68.95; H, 4.63; N, 8.04; Found: $\mathrm{C}, 68.93 ; \mathrm{H}, 4.64 ; \mathrm{N}, 8.05$. MS (ESI) $(m / z):[\mathrm{M}+\mathrm{H}]^{-}$346.90, $[\mathrm{M}]^{+}$347.90, $[\mathrm{M}+\mathrm{H}]^{+} 348.90$.

1-(4-Cyanophenyl)-3-(2-thienyl)-5-(1,3-benzodioxol-5-yl)-2-pyrazoline (4b). Yield: 93\%. M.p.: 156-157 ${ }^{\circ} \mathrm{C}$. IR $v_{\max }\left(\mathrm{cm}^{-1}\right)$ : 3105.39 (aromatic C-H stretching), 2916.37, 2848.86 (aliphatic C-H stretching), 2208.49 ( $C \equiv N$ stretching), 1600.92, 1510.26, 1481.33, 1442.75 ( $C=N$ and $C=C$ stretching), 1396.46, 1325.10, 1242.16, 1174.65, 1095.57, 1035.77 (C-N, C-O stretching and aromatic C-H in plane bending), 935.48, 840.96, 821.68, 802.39, 727.16 (aromatic C-H out of plane bending and C-S stretching). ${ }^{1} \mathrm{H}-\mathrm{NMR}$ $\left(300 \mathrm{MHz}, \mathrm{DMSO}-d_{6}\right) \delta(\mathrm{ppm}): 3.20\left(1 \mathrm{H}, \mathrm{dd}, J_{A M}=17.64 \mathrm{~Hz}, J_{A X}=4.98 \mathrm{~Hz}, \mathrm{C}_{4}-\mathrm{H}_{\mathrm{A}}\right.$ pyrazoline), $3.95\left(1 \mathrm{H}, \mathrm{dd}, J_{M A}=17.64 \mathrm{~Hz}, J_{M X}=11.94 \mathrm{~Hz}, \mathrm{C}_{4}-\mathrm{H}_{\mathrm{M}}\right.$ pyrazoline $), 5.57\left(1 \mathrm{H}, \mathrm{dd}, J_{M X}=11.82 \mathrm{~Hz}\right.$, $J_{A X}=4.92 \mathrm{~Hz}, \mathrm{C}_{5}-\mathrm{H}_{X}$ pyrazoline $), 5.99\left(2 \mathrm{H}, \mathrm{d}, J=1.71 \mathrm{~Hz}, \mathrm{O}-\mathrm{CH}_{2}-\mathrm{O}\right), 6.73(1 \mathrm{H}, \mathrm{dd}, J=7.98 \mathrm{~Hz}, 1.71 \mathrm{~Hz}$, aromatic proton), $6.77(1 \mathrm{H}, \mathrm{d}, J=1.56 \mathrm{~Hz}$, aromatic proton), $6.87(1 \mathrm{H}, \mathrm{d}, J=7.95 \mathrm{~Hz}$, aromatic proton), $7.01(2 \mathrm{H}, \mathrm{d}, J=8.91 \mathrm{~Hz}$, aromatic protons), $7.14(1 \mathrm{H}, \mathrm{dd}, J=5.04 \mathrm{~Hz}, 3.66 \mathrm{~Hz}$, aromatic proton), 7.36 $(1 \mathrm{H}, \mathrm{dd} J=3.60 \mathrm{~Hz}, 1.05 \mathrm{~Hz}$, aromatic proton), $7.57(2 \mathrm{H}, \mathrm{d}, J=8.94 \mathrm{~Hz}$, aromatic protons $), 7.69(1 \mathrm{H}$, $\mathrm{dd}, J=5.04 \mathrm{~Hz}, 1.02 \mathrm{~Hz}$, aromatic proton). ${ }^{13} \mathrm{C}-\mathrm{NMR}\left(75 \mathrm{MHz}, \mathrm{DMSO}-d_{6}\right) \delta(\mathrm{ppm}): 44.26\left(\mathrm{CH}_{2}\right), 62.52$ $(\mathrm{CH}), 99.45(\mathrm{C}), 101.65\left(\mathrm{CH}_{2}\right), 106.41(\mathrm{CH}), 109.20(\mathrm{CH}), 113.21(2 \mathrm{CH}), 119.42(\mathrm{CH}), 120.42(\mathrm{C}), 128.48$ $(\mathrm{CH}), 129.18(\mathrm{CH}), 129.47(\mathrm{CH}), 133.80(2 \mathrm{CH}), 135.24(\mathrm{C}), 135.46(\mathrm{C}), 146.75(\mathrm{C}), 147.24(\mathrm{C}), 147.51(\mathrm{C})$, 148.33 (C). Anal. Calcd. for $\mathrm{C}_{21} \mathrm{H}_{15} \mathrm{~N}_{3} \mathrm{O}_{2} \mathrm{~S}: \mathrm{C}, 67.54 ; \mathrm{H}, 4.05$; N, 11.25; Found: $\mathrm{C}, 67.56 ; \mathrm{H}, 4.04 ; \mathrm{N}, 11.24$. MS (ESI) $(m / z):[\mathrm{M}]^{+} 373.90$.

1-(4-Fluorophenyl)-3-(2-thienyl)-5-(1,3-benzodioxol-5-yl)-2-pyrazoline (4c). Yield: 76\%. M.p.: $108-110{ }^{\circ} \mathrm{C}$. IR $v_{\max }\left(\mathrm{cm}^{-1}\right)$ : 3086.11 (aromatic C-H stretching), 2970.38, 2916.37 (aliphatic C-H stretching), 1504.48, 1483.26, 1442.75 ( $\mathrm{C}=\mathrm{N}$ and C=C stretching), 1240.23, 1220.94, 1035.77 (C-N, C-O stretching and aromatic $\mathrm{C}-\mathrm{H}$ in plane bending), 931.62, 802.39, 705.95 (aromatic C-H out of plane bending and C-S stretching). ${ }^{1} \mathrm{H}-\mathrm{NMR}\left(300 \mathrm{MHz}, \mathrm{DMSO}-d_{6}\right) \delta(\mathrm{ppm}): 3.11\left(1 \mathrm{H}, \mathrm{dd}, J_{A M}=17.31 \mathrm{~Hz}, J_{A X}=6.81 \mathrm{~Hz}, \mathrm{C}_{4}-\mathrm{H}_{\mathrm{A}}\right.$ pyrazoline), 
$3.87\left(1 \mathrm{H}, \mathrm{dd}, J_{M A}=17.31 \mathrm{~Hz}, J_{M X}=11.97 \mathrm{~Hz}, \mathrm{C}_{4}-\mathrm{H}_{\mathrm{M}}\right.$ pyrazoline $), 5.36\left(1 \mathrm{H}, \mathrm{dd}, J_{M X}=11.91 \mathrm{~Hz}\right.$, $J_{A X}=6.75 \mathrm{~Hz}, \mathrm{C}_{5}-\mathrm{H}_{\mathrm{X}}$ pyrazoline $), 5.98\left(2 \mathrm{H}, \mathrm{d}, J=0.78 \mathrm{~Hz}, \mathrm{O}-\mathrm{CH}_{2}-\mathrm{O}\right), 6.77-6.81(2 \mathrm{H}, \mathrm{m}$, aromatic protons), $6.87(1 \mathrm{H}, \mathrm{d}, J=7.83 \mathrm{~Hz}$, aromatic proton), $6.91-6.94(2 \mathrm{H}, \mathrm{m}$, aromatic protons $), 6.95-7.02(2 \mathrm{H}$, $\mathrm{m}$, aromatic protons), 7.04-7.11 $(1 \mathrm{H}, \mathrm{m}$, aromatic proton $), 7.24-7.26(1 \mathrm{H}, \mathrm{m}$, aromatic proton $), 7.60(1 \mathrm{H}$, $\mathrm{dd}, J=5.07 \mathrm{~Hz}, 1.05 \mathrm{~Hz}$, aromatic proton). ${ }^{13} \mathrm{C}-\mathrm{NMR}\left(75 \mathrm{MHz}, \mathrm{DMSO}-d_{6}\right) \delta(\mathrm{ppm}): 44.36\left(\mathrm{CH}_{2}\right), 64.11$ $(\mathrm{CH}), 101.55\left(\mathrm{CH}_{2}\right), 106.62(\mathrm{CH}), 109.08(\mathrm{CH}), 114.65$ and $114.75(2 \mathrm{CH}), 115.75$ and $116.05(2 \mathrm{CH}), 119.70$ (2CH), 127.98 and $128.28(2 \mathrm{CH}), 136.04$ and $136.31(2 \mathrm{C}), 141.49(\mathrm{C}), 144.46(\mathrm{C}), 147.06(\mathrm{C}), 148.22(\mathrm{C})$, 154.85 and 157.96 (C). Anal. Calcd. for $\mathrm{C}_{20} \mathrm{H}_{15} \mathrm{FN}_{2} \mathrm{O}_{2} \mathrm{~S}: \mathrm{C}, 65.56 ; \mathrm{H}, 4.13 ; \mathrm{N}, 7.65$; Found: $\mathrm{C}, 65.54 ; \mathrm{H}$, 4.14; N, 7.66. MS (ESI) $(\mathrm{m} / \mathrm{z}):[\mathrm{M}+\mathrm{H}]^{-} 364.90,[\mathrm{M}]^{+} 365.90,[\mathrm{M}+\mathrm{H}]^{+} 366.90$.

1-(4-Chlorophenyl)-3-(2-thienyl)-5-(1,3-benzodioxol-5-yl)-2-pyrazoline (4d). Yield: 92\%. M.p.: $130-132{ }^{\circ} \mathrm{C}$. IR $v_{\max }\left(\mathrm{cm}^{-1}\right)$ : 3072.60 (aromatic C-H stretching), 2916.37, 2848.86 (aliphatic C-H stretching), 1595.13, $1492.90,1481.33,1442.75$ ( $\mathrm{C}=\mathrm{N}$ and $\mathrm{C}=\mathrm{C}$ stretching), 1382.96, 1319.31, 1244.09, 1136.07, 1093.64, 1037.70 (C-N, C-O stretching and aromatic C-H in plane bending), 933.55, 813.96, 796.60, 725.23, 707.88 (aromatic C-H out of plane bending and C-S stretching). ${ }^{1} \mathrm{H}-\mathrm{NMR}\left(300 \mathrm{MHz}, \mathrm{DMSO}-d_{6}\right) \delta(\mathrm{ppm}): 3.13$ $\left(1 \mathrm{H}, \mathrm{dd}, J_{A M}=17.40 \mathrm{~Hz}, J_{A X}=6.09 \mathrm{~Hz}, \mathrm{C}_{4}-\mathrm{H}_{\mathrm{A}}\right.$ pyrazoline $), 3.89\left(1 \mathrm{H}, \mathrm{dd}, J_{M A}=17.43 \mathrm{~Hz}, J_{M X}=12.03\right.$ $\mathrm{Hz}, \mathrm{C}_{4}-\mathrm{H}_{\mathrm{M}}$ pyrazoline), $5.42\left(1 \mathrm{H}, \mathrm{dd}, J_{M X}=11.94 \mathrm{~Hz}, J_{A X}=6.03 \mathrm{~Hz}, \mathrm{C}_{5}-\mathrm{H}_{X}\right.$ pyrazoline $), 5.98(2 \mathrm{H}, \mathrm{d}$, $\left.J=1.59 \mathrm{~Hz}, \mathrm{O}-\mathrm{CH}_{2}-\mathrm{O}\right), 6.74-6.78(2 \mathrm{H}, \mathrm{m}$, aromatic protons $), 6.87(1 \mathrm{H}, \mathrm{d}, J=7.89 \mathrm{~Hz}$, aromatic proton), $6.94(2 \mathrm{H}, \mathrm{d}, J=9.03 \mathrm{~Hz}$, aromatic protons), $7.11(1 \mathrm{H}, \mathrm{dd}, J=5.07 \mathrm{~Hz}, 3.63 \mathrm{~Hz}$, aromatic proton), 7.20 $(2 \mathrm{H}, \mathrm{d}, J=9.00 \mathrm{~Hz}$, aromatic protons), $7.27(1 \mathrm{H}, \mathrm{dd}, J=3.57 \mathrm{~Hz}, 1.08 \mathrm{~Hz}$, aromatic proton), $7.62(1 \mathrm{H}, \mathrm{dd}$, $J=5.07 \mathrm{~Hz}, 1.05 \mathrm{~Hz}$, aromatic proton). ${ }^{13} \mathrm{C}-\mathrm{NMR}\left(75 \mathrm{MHz}\right.$, DMSO- $\left.d_{6}\right) \delta(\mathrm{ppm}): 44.30\left(\mathrm{CH}_{2}\right), 63.41(\mathrm{CH})$, $101.57\left(\mathrm{CH}_{2}\right), 106.52(\mathrm{CH}), 109.10(\mathrm{CH}), 114.85(2 \mathrm{CH}), 116.52(\mathrm{C}), 119.58(\mathrm{CH}), 122.70(\mathrm{CH}), 128.27(2 \mathrm{CH}$, d, $J=6.75 \mathrm{~Hz}), 129.21(2 \mathrm{CH}, \mathrm{d}, J=6.75 \mathrm{~Hz}), 135.85(\mathrm{C}), 136.06(\mathrm{C}), 143.26(\mathrm{C}), 145.04(\mathrm{C}), 147.09(\mathrm{C})$, 148.24 (C). Anal. Calcd. for $\mathrm{C}_{20} \mathrm{H}_{15} \mathrm{ClN}_{2} \mathrm{O}_{2} \mathrm{~S}: \mathrm{C}, 62.74 ; \mathrm{H}, 3.95 ; \mathrm{N}, 7.32$; Found: $\mathrm{C}, 62.76 ; \mathrm{H}, 3.94 ; \mathrm{N}, 7.31$. MS (ESI) $(\mathrm{m} / \mathrm{z}):[\mathrm{M}+\mathrm{H}]^{--}$378.80, [M] 380.80, [M + H] 381.90, [M + H] ${ }^{++}$382.80, [M + H] ${ }^{+++} 383.90$.

1-(4-Bromophenyl)-3-(2-thienyl)-5-(1,3-benzodioxol-5-yl)-2-pyrazoline (4e). Yield: 90\%. M.p.: 136-138 ${ }^{\circ} \mathrm{C}$. IR $v_{\max }\left(\mathrm{cm}^{-1}\right)$ : 3070.68 (aromatic C-H stretching), 2916.37 (aliphatic C-H stretching), 1589.34, 1481.33, 1442.75 ( $\mathrm{C}=\mathrm{N}$ and $\mathrm{C}=\mathrm{C}$ stretching), 1382.96, 1319.31, 1244.09, 1128.36, 1091.71, 1035.77 (C-N, C-O stretching and aromatic C-H in plane bending), 935.48, 812.03, 707.88 (aromatic C-H out of plane bending and C-S stretching). ${ }^{1} \mathrm{H}-\mathrm{NMR}\left(300 \mathrm{MHz}, \mathrm{DMSO}-d_{6}\right) \delta(\mathrm{ppm}): 3.13\left(1 \mathrm{H}, \mathrm{dd}, J_{A M}=17.40 \mathrm{~Hz}\right.$, $J_{A X}=5.91 \mathrm{~Hz}, \mathrm{C}_{4}-\mathrm{H}_{\mathrm{A}}$ pyrazoline $), 3.88\left(1 \mathrm{H}, \mathrm{dd}, J_{M A}=17.43 \mathrm{~Hz}, J_{M X}=12.09 \mathrm{~Hz}, \mathrm{C}_{4}-\mathrm{H}_{\mathrm{M}}\right.$ pyrazoline $)$, $5.42\left(1 \mathrm{H}, \mathrm{dd}, J_{M X}=11.88 \mathrm{~Hz}, J_{A X}=5.85 \mathrm{~Hz}, \mathrm{C}_{5}-\mathrm{H}_{X}\right.$ pyrazoline $), 5.98\left(2 \mathrm{H}, \mathrm{d}, J=1.56 \mathrm{~Hz}, \mathrm{O}-\mathrm{CH}_{2}-\mathrm{O}\right)$, 6.73-6.77 $(2 \mathrm{H}, \mathrm{m}$, aromatic protons), 6.83-6.94 $(3 \mathrm{H}, \mathrm{m}$, aromatic protons $), 7.10(1 \mathrm{H}, \mathrm{dd}, J=4.89 \mathrm{~Hz}$, $3.75 \mathrm{~Hz}$, aromatic proton), 7.27-7.33 $(3 \mathrm{H}, \mathrm{m}$, aromatic protons $), 7.62(1 \mathrm{H}, \mathrm{d}, J=4.95 \mathrm{~Hz}$, aromatic proton). ${ }^{13} \mathrm{C}-\mathrm{NMR}\left(75 \mathrm{MHz}, \mathrm{DMSO}-d_{6}\right) \delta$ (ppm): $44.29\left(\mathrm{CH}_{2}\right), 63.29(\mathrm{CH}), 101.57\left(\mathrm{CH}_{2}\right), 106.51(\mathrm{CH})$, $109.11(\mathrm{CH}), 110.32(\mathrm{CH}), 115.34(2 \mathrm{CH}), 119.56(\mathrm{CH}), 128.31(2 \mathrm{CH}, \mathrm{d}, J=5.25 \mathrm{~Hz}), 132.00(2 \mathrm{CH}), 135.82$ (C), 136.01 (2C), 143.57 (C), 145.13 (C), 147.10 (C), 148.24 (C). Anal. Calcd. for $\mathrm{C}_{20} \mathrm{H}_{15} \mathrm{BrN}_{2} \mathrm{O}_{2} \mathrm{~S}$ : C, 56.22; H, 3.54; N, 6.56; Found: C, 56.24; H, 3.53; N, 6.55. MS (ESI) $(\mathrm{m} / \mathrm{z})$ : $[\mathrm{M}+\mathrm{H}]^{-} 426.80,[\mathrm{M}]^{+} 427.80$.

1-(4-Methylphenyl)-3-(2-thienyl)-5-(1,3-benzodioxol-5-yl)-2-pyrazoline (4f). Yield: 47\%. M.p.: $153-155^{\circ} \mathrm{C}$. IR $v_{\max }\left(\mathrm{cm}^{-1}\right)$ : 3070.68 (aromatic C-H stretching), 2916.37, 2848.86 (aliphatic C-H stretching), 1593.20, 1481.33, 1442.75 (C=N and C=C stretching), 1382.96, 1319.31, 1244.09, 1130.29, 1091.71, 1035.77 (C-N, C-O stretching and aromatic C-H in plane bending), 933.55, 812.03, 802.39, 723.31, 707.88 (aromatic C-H out of plane bending and C-S stretching). ${ }^{1} \mathrm{H}-\mathrm{NMR}\left(300 \mathrm{MHz}, \mathrm{DMSO}-d_{6}\right) \delta(\mathrm{ppm}): 2.16(3 \mathrm{H}, \mathrm{s}$, $\left.\mathrm{CH}_{3}\right), 3.07\left(1 \mathrm{H}, \mathrm{dd}, J_{A M}=17.28 \mathrm{~Hz}, J_{A X}=6.57 \mathrm{~Hz}, \mathrm{C}_{4}-\mathrm{H}_{\mathrm{A}}\right.$ pyrazoline $), 3.84\left(1 \mathrm{H}, \mathrm{dd}, J_{M A}=17.25 \mathrm{~Hz}\right.$, $J_{M X}=12.03 \mathrm{~Hz}, \mathrm{C}_{4}-\mathrm{H}_{\mathrm{M}}$ pyrazoline $), 5.35\left(1 \mathrm{H}, \mathrm{dd}, J_{M X}=11.97 \mathrm{~Hz}, J_{A X}=6.54 \mathrm{~Hz}, \mathrm{C}_{5}-\mathrm{H}_{X}\right.$ pyrazoline $)$, $5.97\left(2 \mathrm{H}, \mathrm{d}, J=1.26 \mathrm{~Hz}, \mathrm{O}-\mathrm{CH}_{2}-\mathrm{O}\right), 6.76(2 \mathrm{H}, \mathrm{d}, J=6.84 \mathrm{~Hz}$, aromatic protons), $6.86(3 \mathrm{H}, \mathrm{d}, J=8.64 \mathrm{~Hz}$, aromatic protons), $6.97(2 \mathrm{H}, \mathrm{d}, J=8.43 \mathrm{~Hz}$, aromatic protons), $7.09(1 \mathrm{H}, \mathrm{dd}, J=5.04 \mathrm{~Hz}, 3.63 \mathrm{~Hz}$, aromatic proton), $7.22(1 \mathrm{H}, \mathrm{dd}, J=3.54 \mathrm{~Hz}, 0.99 \mathrm{~Hz}$, aromatic proton), $7.57(1 \mathrm{H}, \mathrm{dd}, J=5.04 \mathrm{~Hz}, 0.99 \mathrm{~Hz}$, aromatic proton). ${ }^{13} \mathrm{C}-\mathrm{NMR}\left(75 \mathrm{MHz}, \mathrm{DMSO}-d_{6}\right) \delta(\mathrm{ppm}): 20.54$ and $20.57\left(\mathrm{CH}_{3}\right), 44.14\left(\mathrm{CH}_{2}\right), 63.80$ $(\mathrm{CH}), 101.50\left(\mathrm{CH}_{2}\right), 106.57(\mathrm{CH}), 109.02(\mathrm{CH}), 113.65(2 \mathrm{CH}), 119.63(\mathrm{CH}), 127.61(\mathrm{CH}), 127.88(\mathrm{CH})$, 
$128.24(\mathrm{CH}), 129.78(2 \mathrm{CH}), 136.29(\mathrm{C}), 136.63(2 \mathrm{C}), 142.43(\mathrm{C}), 143.67$ (C), 146.95 (C), 148.14 (C). Anal. Calcd. for $\mathrm{C}_{21} \mathrm{H}_{18} \mathrm{~N}_{2} \mathrm{O}_{2} \mathrm{~S}$ : C, 69.59; H, 5.01; N, 7.73; Found: C, 69.61; H, 5.00; N, 7.72. MS (ESI) (m/z): $[\mathrm{M}+\mathrm{H}]^{--}$360.90, [M] 361.90, [M + H] 362.90.

1-(4-Methoxyphenyl)-3-(2-thienyl)-5-(1,3-benzodioxol-5-yl)-2-pyrazoline (4g). Yield: 39\%. M.p.: $140-142{ }^{\circ} \mathrm{C}$. IR $v_{\max }\left(\mathrm{cm}^{-1}\right)$ : 3107.32 (aromatic C-H stretching), 2916.37, 2848.86 (aliphatic C-H stretching), 1587.42, $1504.48,1487.12,1444.68$ ( $\mathrm{C}=\mathrm{N}$ and $\mathrm{C}=\mathrm{C}$ stretching), 1375.25, 1230.58, 1180.44, 1116.78, 1083.99, 1033.85 (C-N, C-O stretching and aromatic C-H in plane bending), 935.48, 829.39, 804.32, 707.88 (aromatic C-H out of plane bending and C-S stretching). ${ }^{1} \mathrm{H}-\mathrm{NMR}\left(300 \mathrm{MHz}, \mathrm{DMSO}-d_{6}\right) \delta(\mathrm{ppm}): 3.07(1 \mathrm{H}, \mathrm{dd}$, $J_{A M}=17.16 \mathrm{~Hz}, J_{A X}=7.41 \mathrm{~Hz}, \mathrm{C}_{4}-\mathrm{H}_{\mathrm{A}}$ pyrazoline $), 3.65\left(3 \mathrm{H}, \mathrm{s}, \mathrm{OCH}_{3}\right), 3.83\left(1 \mathrm{H}, \mathrm{dd}, J_{M A}=17.19 \mathrm{~Hz}\right.$, $J_{M X}=11.94 \mathrm{~Hz}, \mathrm{C}_{4}-\mathrm{H}_{\mathrm{M}}$ pyrazoline), $5.29\left(1 \mathrm{H}, \mathrm{dd}, J_{M X}=11.85 \mathrm{~Hz}, J_{A X}=7.38 \mathrm{~Hz}, \mathrm{C}_{5}-\mathrm{H}_{X}\right.$ pyrazoline $)$, $5.98\left(2 \mathrm{H}, \mathrm{d}, J=0.81 \mathrm{~Hz}, \mathrm{O}-\mathrm{CH}_{2}-\mathrm{O}\right), 6.76-6.81(4 \mathrm{H}, \mathrm{m}$, aromatic protons), 6.85-6.91 (3H, m, aromatic protons), $7.09(1 \mathrm{H}, \mathrm{dd}, J=5.04 \mathrm{~Hz}, 3.60 \mathrm{~Hz}$, aromatic proton), $7.21(1 \mathrm{H}, \mathrm{dd}, J=3.54 \mathrm{~Hz}, 1.02 \mathrm{~Hz}$, aromatic proton), $7.56\left(1 \mathrm{H}, \mathrm{dd}, J=5.04 \mathrm{~Hz}, 1.02 \mathrm{~Hz}\right.$, aromatic proton). ${ }^{13} \mathrm{C}-\mathrm{NMR}\left(75 \mathrm{MHz}, \mathrm{DMSO}-d_{6}\right) \delta$ (ppm): $44.24\left(\mathrm{CH}_{2}\right), 55.64$ and $55.67\left(\mathrm{CH}_{3}\right), 64.66(\mathrm{CH}), 101.50\left(\mathrm{CH}_{2}\right), 106.71(\mathrm{CH}), 109.01(\mathrm{CH}), 114.83$ $(2 \mathrm{CH}), 115.05(2 \mathrm{CH}), 119.82(\mathrm{CH}), 127.46(2 \mathrm{CH}, \mathrm{d}, J=6.00 \mathrm{~Hz}), 128.22(\mathrm{CH}), 136.37(\mathrm{C}), 136.63(\mathrm{C})$, 139.11 (C), 143.49 (C), 146.97 (C), 148.14 (C), 153.25 (C). Anal. Calcd. for $\mathrm{C}_{21} \mathrm{H}_{18} \mathrm{~N}_{2} \mathrm{O}_{3} \mathrm{~S}: \mathrm{C}, 66.65 ; \mathrm{H}$, 4.79; N, 7.40; Found: C, 66.67; H, 4.78; N, 7.39. MS (ESI) (m/z): [M] $]^{+} 377.90,[\mathrm{M}+\mathrm{H}]^{+} 378.90$.

1-(4-Methylsulfonylphenyl)-3-(2-thienyl)-5-(1,3-benzodioxol-5-yl)-2-pyrazoline (4h). Yield: 63\%. M.p.: 172-173 ${ }^{\circ} \mathrm{C}$. IR $v_{\max }\left(\mathrm{cm}^{-1}\right)$ : 3097.68 (aromatic C-H stretching), 2985.81, 2900.84 (aliphatic C-H stretching), 1589.34, 1502.55, 1483.26, 1442.75 ( $\mathrm{C}=\mathrm{N}$ and $\mathrm{C}=\mathrm{C}$ stretching), 1392.61, 1381.03, 1296.16, $1247.94,1078.21,1051.20$ (C-N, C-O stretching and aromatic C-H in plane bending), 821.68, 769.60, 705.95 (aromatic C-H out of plane bending and C-S stretching). ${ }^{1} \mathrm{H}-\mathrm{NMR}\left(300 \mathrm{MHz}, \mathrm{DMSO}-d_{6}\right) \delta$ (ppm): $3.07\left(3 \mathrm{H}, \mathrm{s}, \mathrm{SO}_{2} \mathrm{CH}_{3}\right), 3.20\left(1 \mathrm{H}, \mathrm{dd}, J_{A M}=17.64 \mathrm{~Hz}, J_{A X}=5.07 \mathrm{~Hz}, \mathrm{C}_{4}-\mathrm{H}_{\mathrm{A}}\right.$ pyrazoline $), 3.96(1 \mathrm{H}$, $\mathrm{dd}, J_{M A}=17.61 \mathrm{~Hz}, J_{M X}=11.94 \mathrm{~Hz}, \mathrm{C}_{4}-\mathrm{H}_{\mathrm{M}}$ pyrazoline $), 5.57\left(1 \mathrm{H}, \mathrm{dd}, J_{M X}=11.85 \mathrm{~Hz}, J_{A X}=4.98 \mathrm{~Hz}\right.$, $\mathrm{C}_{5}-\mathrm{H}_{X}$ pyrazoline), $5.98\left(2 \mathrm{H}, \mathrm{d}, J=1.62 \mathrm{~Hz}, \mathrm{O}-\mathrm{CH}_{2}-\mathrm{O}\right), 6.75(1 \mathrm{H}, \mathrm{dd}, J=7.95 \mathrm{~Hz}, 1.74 \mathrm{~Hz}$, aromatic proton), $6.79(1 \mathrm{H}, \mathrm{d}, J=1.56 \mathrm{~Hz}$, aromatic proton), $6.88(1 \mathrm{H}, \mathrm{d}, J=7.92 \mathrm{~Hz}$, aromatic proton), 7.07 $(2 \mathrm{H}, \mathrm{d}, J=8.94 \mathrm{~Hz}$, aromatic protons $), 7.13(1 \mathrm{H}, \mathrm{dd}, J=5.07 \mathrm{~Hz}, 3.66 \mathrm{~Hz}$, aromatic proton $), 7.36(1 \mathrm{H}$, $\mathrm{dd}, J=3.57 \mathrm{~Hz}, 1.05 \mathrm{~Hz}$, aromatic proton), 7.65-7.69 (3H, m, aromatic protons). ${ }^{13} \mathrm{C}-\mathrm{NMR}(75 \mathrm{MHz}$, DMSO- $\left.d_{6}\right) \delta(\mathrm{ppm}): 44.29\left(\mathrm{CH}_{2}\right), 44.63\left(\mathrm{CH}_{3}\right), 62.61(\mathrm{CH}), 101.64\left(\mathrm{CH}_{2}\right), 106.43(\mathrm{CH}), 109.21(\mathrm{CH})$, $112.61(2 \mathrm{CH}), 119.45(\mathrm{CH}), 128.47(\mathrm{CH}), 129.05(2 \mathrm{CH}), 129.38(2 \mathrm{CH}), 129.61(\mathrm{C}), 135.30(\mathrm{C}), 135.56(2 \mathrm{C})$, 147.27 (2C), 148.32 (C). Anal. Calcd. for $\mathrm{C}_{21} \mathrm{H}_{18} \mathrm{~N}_{2} \mathrm{O}_{4} \mathrm{~S}_{2}$ : C, 59.14; $\mathrm{H}, 4.25 ; \mathrm{N}, 6.57$; Found: $\mathrm{C}, 59.16$; $\mathrm{H}$, 4.24; N, 6.56. MS (ESI) $(m / z):[M]^{+} 426.80,[\mathrm{M}+\mathrm{H}]^{+} 427.80$.

1-(4-Sulfonamidophenyl)-3-(2-thienyl)-5-(1,3-benzodioxol-5-yl)-2-pyrazoline (4i) [45]. Yield: 83\%. M.p.: $129-130{ }^{\circ} \mathrm{C}$. IR $v_{\max }\left(\mathrm{cm}^{-1}\right)$ : 3321.42, 3250.05 (N-H stretching), 3103.46, 3074.53 (aromatic $\mathrm{C}-\mathrm{H}$ stretching), 2916.37, 2848.86 (aliphatic C-H stretching), 1591.27, 1502.55, 1485.19, 1442.75 (C=N and C=C stretching), 1394.53, 1323.17, 1307.74, 1238.30, 1151.10, 1095.57, 1035.77, 1001.06 (C-N, C-O stretching and aromatic $\mathrm{C}-\mathrm{H}$ in plane bending), 933.55, 904.61, 860.25, 812.03, 713.66 (aromatic $\mathrm{C}-\mathrm{H}$ out of plane bending and C-S stretching). ${ }^{1} \mathrm{H}-\mathrm{NMR}\left(300 \mathrm{MHz}, \mathrm{DMSO}-d_{6}\right) \delta(\mathrm{ppm}): 3.18\left(1 \mathrm{H}, \mathrm{dd}, J_{A M}=17.52 \mathrm{~Hz}\right.$, $J_{A X}=5.10 \mathrm{~Hz}, \mathrm{C}_{4}-\mathrm{H}_{\mathrm{A}}$ pyrazoline $), 3.93\left(1 \mathrm{H}, \mathrm{dd}, J_{M A}=17.52 \mathrm{~Hz}, J_{M X}=11.94 \mathrm{~Hz}, \mathrm{C}_{4}-\mathrm{H}_{\mathrm{M}}\right.$ pyrazoline $), 5.56$ $\left(1 \mathrm{H}, \mathrm{dd}, J_{M X}=11.85 \mathrm{~Hz}, J_{A X}=5.01 \mathrm{~Hz}, \mathrm{C}_{5}-\mathrm{H}_{X}\right.$ pyrazoline $), 5.98\left(2 \mathrm{H}, \mathrm{d}, J=2.04 \mathrm{~Hz}, \mathrm{O}-\mathrm{CH}_{2}-\mathrm{O}\right), 6.72-6.77$ $(2 \mathrm{H}, \mathrm{m}$, aromatic protons), $6.87(1 \mathrm{H}, \mathrm{d}, J=7.86 \mathrm{~Hz}$, aromatic proton), 7.01-7.04 $(4 \mathrm{H}, \mathrm{m}$, aromatic and $\mathrm{NH}_{2}$ protons), $7.12(1 \mathrm{H}, \mathrm{dd}, J=5.04 \mathrm{~Hz}, 3.63 \mathrm{~Hz}$, aromatic proton), $7.33(1 \mathrm{H}, \mathrm{dd}, J=3.57 \mathrm{~Hz}, 1.05 \mathrm{~Hz}$, aromatic proton), $7.60(2 \mathrm{H}, \mathrm{d}, J=8.94 \mathrm{~Hz}$, aromatic protons), $7.66(1 \mathrm{H}, \mathrm{dd}, J=5.04 \mathrm{~Hz}, 1.02 \mathrm{~Hz}$, aromatic proton). ${ }^{13} \mathrm{C}-\mathrm{NMR}\left(75 \mathrm{MHz}\right.$, DMSO- $\left.d_{6}\right) \delta$ (ppm): $44.83\left(\mathrm{CH}_{2}\right), 64.86(\mathrm{CH}), 101.66\left(\mathrm{CH}_{2}\right), 106.85(\mathrm{CH})$, $109.87(\mathrm{CH}), 115.65(2 \mathrm{CH}), 119.87(\mathrm{CH}), 127.47(\mathrm{CH}), 127.96(\mathrm{CH}), 128.05(\mathrm{CH}), 131.88(2 \mathrm{CH}), 135.77$ (C), 136.45 (C), 146.03 (C), 147.49 (C), 148.90 (C), 159.36 (2C). Anal. Calcd. for $\mathrm{C}_{20} \mathrm{H}_{17} \mathrm{~N}_{3} \mathrm{O}_{4} \mathrm{~S}_{2}$ : C, 56.19; H, 4.01; N, 9.83; Found: C, 56.24; H, 4.08; N, 9.80. MS (ESI) $(\mathrm{m} / \mathrm{z})$ : [M] ${ }^{+} 427.80,[\mathrm{M}+\mathrm{H}]^{+} 428.80$. 


\subsection{Pharmacology}

\subsubsection{Cell Culture}

PC-12 Adh cells were cultured in 10\% horse serum, 5\% fetal bovine serum, and 1\% penicillin-streptomycin containing DMEM growth medium, at $37{ }^{\circ} \mathrm{C}$ in a humidified incubator with $5 \% \mathrm{CO}_{2}$. The proliferating cells were passaged $1: 2$ to new 25 and/or $75 \mathrm{~cm}^{2}$ flasks and cell stocks were prepared in order to use in future experiments. In order to induce PC-12 Adh cell differentiation into neuronal phenotype, growth medium was changed with $1 \%$ fetal bovine serum, $1 \%$ penicillin-streptomycin and $100 \mathrm{nM}$ NGF containing DMEM differentiation medium.

Differentiated PC-12 Adh cells were stained with Trypan blue solution and counted by a cell counter device (Cedex XS, Innovatis, Malvern, PA, USA) in order to determine the appropriate cell numbers before the experiments.

\subsubsection{Determination of Non-Cytotoxic Concentrations}

In order to obtain non-cytotoxic concentrations of the compounds, the viability of neuronal cells was measured by using 2-(4-iodophenyl)-3-(4-nitrophenyl)-5-(2,4-disulfophenyl)-2H-tetrazolium sodium salt (WST-1) assay (Roche, Mannheim, Germany). The test is based on the cleavage of the tetrazolium salt WST-1 in formazan by mitochondrial dehydrogenases in viable cells. The formazan dye was quantified in a scanning multiwell spectrophotometer by measuring the absorbance of the dye at $420 \mathrm{~nm}$. The differentiated PC-12 Adh cells were scratched and plated onto 96-well culture plates at $5 \times 10^{3}$ density per well. After $24 \mathrm{~h}$, the cells were treated with 400, 200, 100, 50, and $25 \mu \mathrm{g} / \mathrm{mL}$ concentrations of compounds and 400, 200, 100, 50 and $25 \mu \mathrm{M}$ 6-OHDA for $24 \mathrm{~h}$. After the incubation period, the cell proliferation reagent WST-1 $(10 \mu \mathrm{L}$ per well) was added to the wells; and absorbances were measured after $3 \mathrm{~h}$ using a Cytation 3 cell imaging multi-mode reader at $420 \mathrm{~nm}$ (BioTek, Winooski, VT, USA). The measured absorbances directly correlated to the number of viable cells. The cell viability rates were expressed as a percentage of the controls, and $\mathrm{IC}_{50}$ values of the compounds and 6-OHDA were calculated according to the control group [46].

\subsubsection{Determination of Neuroprotective Activity against 6-OHDA-Induced Neurodegeneration}

In order to determine the in vitro neuroprotective potentials of the compounds, 6-OHDA-induced neurotoxicity model of PD was conducted $[47,48]$. The differentiated PC-12 Adh cells were scratched and plated onto 96-well culture plates at $5 \times 10^{3}$ density per well. After $24 \mathrm{~h}$, the cells were treated with $100 \mu \mathrm{g} / \mathrm{mL}$ concentration (only $10 \mu \mathrm{g} / \mathrm{mL}$ and $100 \mu \mathrm{g} / \mathrm{mL}$ were tested for compound 1 , which was found to be highly cytotoxic) of the compounds for $6 \mathrm{~h} .100 \mu \mathrm{g} / \mathrm{mL}$ concentration of the compounds was determined as the non-cytotoxic concentration, and the IC $_{50}$ value of the 6-OHDA $(150 \mu \mathrm{M})$ was used as a positive control according to the WST-1 cell viability assay results. After a 6-h incubation period with the compounds, the medium was removed, and the cells were treated with $150 \mu \mathrm{M}$ 6-OHDA in order to induce neurodegeneration via oxidative stress for $24 \mathrm{~h}$. The control cells were cultured in differentiation medium containing $0.1 \%$ DMSO, and the cells cultured in $150 \mu \mathrm{M}$ 6-OHDA were used as a positive control. After $24 \mathrm{~h}$, the neuroprotective effects of the compounds were determined by WST-1 cell viability assay as explained above. The graphics were drawn according to the cell viability, which was expressed as percentage of the surviving control cells in the study.

\subsubsection{Statistical Analysis}

The graphics were drawn with Graphpad Prism 6.0 software and statistically analyzed using one-way ANOVA and Tukey's post hoc test. The results are expressed as mean \pm standard deviation and the means of three independent experiments $(n=8)$, n.s; $p>0.05,{ }^{*} p<0.05,{ }^{* *} p<0.01$, ${ }^{* * *} p<0.001$, and ${ }^{* * * *} p<0.0001$ were considered significant compared with the control group and the 6-OHDA-positive control group. 


\subsection{Prediction of Pharmacokinetic Parameters}

ADME properties of compounds 1, 2, 3a-i, and 4a-i were in silico predicted using QikProp program (Schrödinger Release 2016-2: QikProp, Schrödinger, LLC, New York, NY, USA, 2016). This program computes physically significant descriptors and pharmaceutically relevant properties, such as QPlogBB, CNS activity, SASA (in square angstroms using a probe with a $1.4 \AA$ Radius) and a percentage of human oral absorption. The acceptability of compounds 1, 2, 3a-i and $4 \mathbf{a}-\mathbf{i}$, based on the Lipinski's rule of five [39] and Jorgensen's rule of three [40], was also determined.

\section{Conclusions}

In the recent work, 2-pyrazoline based compounds $\mathbf{3 a}-\mathbf{i}$ and $4 \mathbf{a}-\mathbf{i}$ were synthesized based on the reaction of chalcones $(\mathbf{1}, \mathbf{2})$ and phenylhydrazine hydrochloride derivatives. All these compounds were evaluated for their neuroprotective effects against toxicity induced by 6-OHDA in rat pheochromocytoma (PC-12) cells. According to in vitro studies, 4-methylsulfonylphenyl containing compounds $3 \mathrm{~h}$ and $4 \mathrm{~h}$ induced cell viability percentage notably when compared with the 6-OHDA-positive control group. In silico ADME prediction also pointed out that all compounds were within the acceptable range for some pharmacokinetic parameters especially important for CNS activity. Consequently, compounds $3 \mathrm{~h}$ and $4 \mathrm{~h}$ stand out as potential orally bioavailable CNS acting drug candidates for further neuroprotective studies associated with PD.

Author Contributions: A.Ö., B.S., and M.D.A. designed the research, A.Ö., B.S., and M.D.A. performed the synthetic work. B.S. carried out the ADME studies and mainly wrote the manuscript. M.D. and E.K.T. performed the whole pharmacology part of this study. A.Ö. was also responsible for the correspondence of the manuscript. All the authors discussed, edited, and approved the final version of the manuscript.

Funding: This study was supported by Anadolu University Scientific Research Projects Commission under the grant no: 1805 S208.

Conflicts of Interest: The authors declare no conflicts of interest.

\section{References}

1. Peden, A.H.; Ironside, J.W. Molecular pathology in neurodegenerative diseases. Curr. Drug Targets 2012, 13, 1548-1559. [CrossRef] [PubMed]

2. Dugger, B.N.; Dickson, D.W. Pathology of neurodegenerative diseases. Cold Spring Harb. Perspect. Biol. 2017, 9, a028035. [CrossRef] [PubMed]

3. Gitler, A.D.; Dhillon, P.; Shorter, J. Neurodegenerative disease: Models, mechanisms, and a new hope. Dis. Model. Mech. 2017, 10, 499-502. [CrossRef] [PubMed]

4. Yacoubian, T.A. Neurodegenerative disorders: Why do we need new therapies? In Drug Discovery Approaches for the Treatment of Neurodegenerative Disorders: Alzheimer's Disease, 1st ed.; Adejare, A., Ed.; Academic Press: London, UK, 2017; Volume 1, pp. 1-16.

5. Brettschneider, J.; Del Tredici, K.; Lee, V.M.; Trojanowski, J.Q. Spreading of pathology in neurodegenerative diseases: A focus on human studies. Nat. Rev. Neurosci. 2015, 16, 109-120. [CrossRef] [PubMed]

6. Williams-Gray, C.H.; Worth, P.F. Parkinson's disease. Medicine 2016, 44, 542-546. [CrossRef]

7. Deng, H.; Wang, P.; Jankovic, J. The genetics of Parkinson disease. Ageing Res. Rev. 2018, 42, 72-85. [CrossRef] [PubMed]

8. Lees, A.J.; Hardy, J.; Revesz, T. Parkinson's disease. Lancet 2009, 373, 2055-2066. [CrossRef]

9. Youdim, M.B.; Kupershmidt, L.; Amit, T.; Weinreb, O. Promises of novel multi-target neuroprotective and neurorestorative drugs for Parkinson's disease. Parkinsonism Relat. Disord. 2014, 20, 132-136. [CrossRef]

10. Yacoubian, T.A.; Standaert, D.G. Targets for neuroprotection in Parkinson's disease. Biochim. Biophys. Acta 2009, 1792, 676-687. [CrossRef] [PubMed]

11. Newland, B.; Dunnett, S.B.; Dowd, E. Targeting delivery in Parkinson's disease. Drug Discov. Today 2016, 21, 1313-1320. [CrossRef] [PubMed]

12. Dexter, D.T.; Jenner, P. Parkinson disease: From pathology to molecular disease mechanisms. Free Radic. Biol. Med. 2013, 62, 132-144. [CrossRef] [PubMed] 
13. Al-Radaideh, A.M.; Rababah, E.M. The role of magnetic resonance imaging in the diagnosis of Parkinson's disease: A review. Clin. Imaging 2016, 40, 987-996. [CrossRef] [PubMed]

14. Eriksen, J.L.; Petrucelli, L. Parkinson's disease-Molecular mechanisms of disease. Drug Discov. Today Dis. Mech. 2004, 1, 399-405. [CrossRef]

15. De Virgilio, A.; Greco, A.; Fabbrini, G.; Inghilleri, M.; Rizzo, M.I.; Gallo, A.; Conte, M.; Rosato, C.; Ciniglio Appiani, M.; de Vincentiis, M. Parkinson's disease: Autoimmunity and neuroinflammation. Autoimmun. Rev. 2016, 15, 1005-1011. [CrossRef] [PubMed]

16. Ellis, J.M.; Fell, M.J. Current approaches to the treatment of Parkinson's disease. Bioorg. Med. Chem. Lett. 2017, 27, 4247-4255. [CrossRef] [PubMed]

17. Shimohama, S.; Sawada, H.; Kitamura, Y.; Taniguchi, T. Disease model: Parkinson's disease. Trends Mol. Med. 2003, 9, 360-365. [CrossRef]

18. Rezak, M. Current pharmacotherapeutic treatment options in Parkinson's disease. Dis. Mon. 2007, 53, $214-222$. [CrossRef] [PubMed]

19. Abushouk, A.I.; Negida, A.; Ahmed, H.; Abdel-Daim, M.M. Neuroprotective mechanisms of plant extracts against MPTP induced neurotoxicity: Future applications in Parkinson's disease. Biomed. Pharmacother. 2017, 85, 635-645. [CrossRef] [PubMed]

20. Francardo, V.; Schmitz, Y.; Sulzer, D.; Cenci, M.A. Neuroprotection and neurorestoration as experimental therapeutics for Parkinson's disease. Exp. Neurol. 2017, 298, 137-147. [CrossRef] [PubMed]

21. Kuruvilla, K.P.; Nandhu, M.S.; Paul, J.; Paulose, C.S. Oxidative stress mediated neuronal damage in the corpus striatum of 6-hydroxydopamine lesioned Parkinson's rats: Neuroprotection by serotonin, GABA and bone marrow cells supplementation. J. Neurol. Sci. 2013, 331, 31-37. [CrossRef] [PubMed]

22. Lazzarini, M.; Martin, S.; Mitkovski, M.; Vozari, R.R.; Stühmer, W.; Bel, E.D. Doxycycline restrains glia and confers neuroprotection in a 6-OHDA Parkinson model. Glia 2013, 61, 1084-1100. [CrossRef] [PubMed]

23. Magalingam, K.B.; Radhakrishnan, A.; Haleagrahara, N. Protective effects of flavonol isoquercitrin, against 6-hydroxy dopamine (6-OHDA)-induced toxicity in PC12 cells. BMC Res. Notes 2014, 7, 49. [CrossRef] [PubMed]

24. Park, H.J.; Zhao, T.T.; Lee, K.S.; Lee, S.H.; Shin, K.S.; Park, K.H.; Choi, H.S.; Lee, M.K. Effects of (-)-sesamin on 6-hydroxydopamine-induced neurotoxicity in PC12 cells and dopaminergic neuronal cells of Parkinson's disease rat models. Neurochem. Int. 2015, 83, 19-27. [CrossRef] [PubMed]

25. Shaaban, M.R.; Mayhoub, A.S.; Farag, A.M. Recent advances in the therapeutic applications of pyrazolines. Expert. Opin. Ther. Pat. 2012, 22, 253-291. [CrossRef] [PubMed]

26. Marella, A.; Ali, M.R.; Alam, M.T.; Saha, R.; Tanwar, O.; Akhter, M.; Shaquiquzzaman, M.; Alam, M.M. Pyrazolines: A biological review. Mini. Rev. Med. Chem. 2013, 13, 921-931. [CrossRef] [PubMed]

27. Alex, J.M.; Kumar, R. 4,5-Dihydro-1H-pyrazole: An indispensable scaffold. J. Enzyme Inhib. Med. Chem. 2014, 29, 427-442. [CrossRef] [PubMed]

28. Tripathi, A.C.; Upadhyay, S.; Paliwal, S.; Saraf, S.K. Privileged scaffolds as MAO inhibitors: Retrospect and prospects. Eur. J. Med. Chem. 2018, 145, 445-497. [CrossRef] [PubMed]

29. Özdemir, A.; Altıntop, M.D.; Kaplancıklı, Z.A.; Turan-Zitouni, G.; Akalın Ciftçi, G.; Ulusoylar Yıldırım, Ş. Synthesis of 1-acetyl-3-(2-thienyl)-5-aryl-2-pyrazoline derivatives and evaluation of their anticancer activity. J. Enzyme Inhib. Med. Chem. 2013, 28, 1221-1227. [CrossRef] [PubMed]

30. Özdemir, A.; Altıntop, M.D.; Kaplancıklı, Z.A.; Turan-Zitouni, G.; Akalın Ciftçi, G.; Demirci, F. Synthesis and biological evaluation of a new series of pyrazolines as new anticandidal agents. Pharm. Chem. J. 2014, 48, 603-612. [CrossRef]

31. Koçyiğit-Kaymakçığlu, B.; Beyhan, N.; Tabanca, N.; Ali, A.; Wedge, D.E.; Duke, S.O.; Bernier, U.R.; Khan, I.A. Discovery and structure activity relationships of 2-pyrazolines derived from chalcones from a pest management perspective. Med. Chem. Res. 2015, 24, 3632-3644. [CrossRef]

32. Sever, B.; Altıntop, M.D.; Karaca Gencer, H.; Kapkac, H.A.; Atli, O.; Baysal, M.; Özdemir, A. Synthesis of new thiazolyl-pyrazoline derivatives and evaluation of their antimicrobial, cytotoxic and genotoxic effects. Lett. Drug Des. Discov. 2018, 15, 744-756. [CrossRef]

33. Özdemir, A.; Altıntop, M.D.; Kaplancıklı, Z.A.; Can, Ö.D.; Demir Özkay, Ü.; Turan-Zitouni, G. Synthesis and evaluation of new 1,5-diaryl-3-[4-(methyl-sulfonyl)phenyl]-4,5-dihydro-1H-pyrazole derivatives as potential antidepressant agents. Molecules 2015, 20, 2668-2684. [CrossRef] [PubMed] 
34. Özdemir, A.; Sever, B.; Altıntop, M.D. New benzodioxole-based pyrazoline derivatives: Synthesis and anticandidal, in silico ADME, molecular docking studies. Lett. Drug Des. Discov. 2018. [CrossRef]

35. Frecer, V.; Berti, F.; Benedetti, F.; Miertus, S. Design of peptidomimetic inhibitors of aspartic protease of HIV-1 containing-Phe $\psi$ Pr-core and displaying favourable ADME-related properties. J. Mol. Graph. Model. 2008, 27, 376-387. [CrossRef] [PubMed]

36. Pardridge, W.M. Drug and gene delivery to the brain: The vascular route. Neuron 2002, 36, 555-558. [CrossRef]

37. Ghose, A.K.; Herbertz, T.; Hudkins, R.L.; Dorsey, B.D.; Mallamo, J.P. Knowledge-based, central nervous system (CNS) lead selection and lead optimization for CNS drug discovery. ACS Chem. Neurosci. 2012, 3, 50-68. [CrossRef] [PubMed]

38. Durham, E.; Dorr, B.; Woetzel, N.; Staritzbichler, R.; Meiler, J. Solvent accessible surface area approximations for rapid and accurate protein structure prediction. J. Mol. Model. 2009, 15, 1093-1108. [CrossRef] [PubMed]

39. Lipinski, C.A.; Lombardo, F.; Dominy, B.W.; Feeney, P.J. Experimental and computational approaches to estimate solubility and permeability in drug discovery and development settings. Adv. Drug Deliv. Rev. 2001, 46, 3-26. [CrossRef]

40. Jorgensen, W.L.; Duffy, E.M. Prediction of drug solubility from structure. Adv. Drug Deliv. Rev. 2002, 54, 355-366. [CrossRef]

41. Zhang, M.; Xi, J.; Ruzi, R.; Li, N.; Wu, Z.; Li, W. Domino-fluorination-protodefluorination enables decarboxylative cross-coupling of $\alpha$-oxocarboxylic acids with styrene via photoredox catalysis. J. Org. Chem. 2017, 82, 9305-9311. [CrossRef] [PubMed]

42. Basaif, S.A.; Sobahi, T.R.; Khalil, A.K.; Hassan, M.A. Stereoselective crossed-aldol condensation of hetarylmethyl ketones with aromatic aldehydes in water: Synthesis of (2E)-3-aryl-1-hetarylprop-2-en-1-ones. Bull. Korean Chem. Soc. 2005, 26, 1677-1681. [CrossRef]

43. Adibi, H.; Hajipour, A.R.; Jafari, H. Metal-free oxidative dehydrogenation of imidazolines and pyrazolines using silica-adsorbed peroxymonosulfate under aprotic and almost neutral conditions. Chem. Heterocycl. Comp. 2008, 44, 802. [CrossRef]

44. Pragst, F.; Weber, F.G. Electrochemical behavior of $N$-aryl- $\Delta 2$-pyrazolines. VIII. Relations between the anodic and cathodic behavior and the absorption and fluorescence properties of $N$-aryl- $\Delta 2$-pyrazolines. J. Prakt. Chem. 1976, 318, 51-68. [CrossRef]

45. Basaif, S.A.; Albar, H.A.; Faidallah, H.M. Synthesis of new pyrazoline and pyrazole derivatives. Indian J. Heterocycl. Chem. 1995, 5, 121-124.

46. Engür, S.; Dikmen, M.; Öztürk, Y. Comparison of antiproliferative and apoptotic effects of a novel proteasome inhibitor MLN2238 with bortezomib on K562 chronic myeloid leukemia cells. Immunopharmacol. Immunotoxicol. 2016, 38, 87-97. [CrossRef] [PubMed]

47. Liu, H.; Mao, P.; Wang, J.; Wang, T.; Xie, C.H. Allicin protects PC12 cells against 6-OHDA-induced oxidative stress and mitochondrial dysfunction via regulating mitochondrial dynamics. Cell. Physiol. Biochem. 2015, 36, 966-979. [CrossRef] [PubMed]

48. Zou, X.D.; Guo, S.Q.; Hu, Z.W.; Li, W.L. NAMPT protects against 6-hydroxydopamine-induced neurotoxicity in PC12 cells through modulating SIRT1 activity. Mol. Med. Rep. 2016, 13, 4058-4064. [CrossRef] [PubMed]

Sample Availability: Samples of the compounds 1, 2, 3a-i, 4a-i are available from the authors. 